\title{
Análise da acessibilidade a hospitais: Estudo de caso para as cidades de São Carlos (SP) e Rio Claro (SP)
}

\author{
A comparative analysis of hospital accessibility: A study case in the \\ municipalities of Rio Claro and Sao Carlos
}

Patrícia Baldini de Medeiros Garcia, Archimedes Azevedo Raia Jr.

Universidade Federal de São Carlos (UFSCar), São Carlos, SP, Brasil

\section{Resumo}

Os hospitais podem causar impactos significativos nos seus arredores e também nos sistemas de transporte da região que estão inseridos, caracterizando-os como potenciais Polos Geradores de Viagens (PGV). Nesse sentido, este artigo aborda a acessibilidade a um hospital do tipo "Santa Casa", com análise feita considerando-se os três modos de viagem: a pé, automóvel e transporte público coletivo (ônibus) nas cidades de Rio Claro/SP e São Carlos/SP. O método proposto baseia-se em indicadores (tempo) para se medir essa acessibilidade fazendo-se o uso de SIGs. Dados do Censo 2000 do IBGE foram utilizados para estimativas das faixas de rendimento médio de setores censitários. Pesquisa com usuários dos hospitais foram realizadas para caracterização dos perfis desses usuários e localização da origem das viagens. Com isso, realizou-se uma análise comparativa entre a acessibilidade, segundo as faixas de rendimento médio do setor censitário, para verificar se realmente a parcela da população que mais necessita e utiliza desse serviço possui níveis de acessibilidade compatíveis.

Palavras-chave: Acessibilidade. Polos Geradores de Viagens. Transporte.

\section{Abstract}

Hospitals can significantly impact their surroundings and the transport system of the region they are located, characterizing them as trip generators. With this regard, this study aimed to perform an analysis of the levels of accessibility to hospitals, such as "Santa Casa", located in the municipalities of Rio Claro and Sao Carlos, considering three ways of traveling: walking, driving, and taking public transport. The proposed method is based on an indicator (time) to measure accessibility to hospitals, making use of geographic information systems. IBGE data were used to estimate the income levels of the traffic areas studied. A survey with the users of hospitals located in the municipalities of Rio Claro and Sao Carlos was performed to characterize the source and location of the travel. A comparative analysis of accessibility was carried out, according to income levels, to verify whether the portion of the population who actually needs and uses hospital services benefits from compatible accessibility levels.

Keywords: Accessibility. Trip generation centers. Transportation.

PBMG é Engenheira, mestre em Engenharia Urbana, e-mail: patriciabmedeiros@hotmail.com AARJr é Engenheiro, doutor em Engenharia de Transportes, e-mail: raiajr@ufscar.br 


\section{Introdução}

0 intenso crescimento das cidades gerou aumento em distâncias que não podem ser percorridas a pé ou de bicicleta. Assim, a dependência do transporte motorizado tornou-se inevitável em cidades grandes e médias, exigindo um planejamento da oferta e operação dos meios de transporte, principalmente daqueles relacionados a transporte coletivo (Vasconcellos, 1995). 0 crescimento desordenado das cidades pode demonstrar a ausência ou inadequação de seus planejamentos, gerando conflitos em diversos setores, principalmente nas áreas de trânsito e transportes. Esses impactos, muitas vezes, são percebidos apenas quando a situação já está caótica e as medidas a serem tomadas são apenas no sentido de remediar e amenizar os impactos.

Grandes empreendimentos, denominados Polos Geradores de Viagens (PGVs), podem causar muitos impactos, sobretudo no que se refere à questão do trânsito e transportes. Esse pode ser o caso, por exemplo, de hospitais (Raia et al., 2012). Por serem, muitas vezes, implementados sem o devido planejamento ou em épocas em que o problema não era significativo, os PGVs provocam inúmeros impactos indesejáveis na fluidez e na segurança do trânsito e também nas áreas de entorno. No entanto, esses impactos, em alguns casos, podem ser até desejáveis, como, por exemplo, valorização dos imóveis lindeiros e melhoria do sistema de transporte coletivo (Raia et al., 2008).

Segundo ANTP (2013), uma gestão de qualidade no setor público implica no conhecimento e aplicação de vários fundamentos de gestão, dentre eles podemse citar: conhecer adequadamente o seu cliente (usuário/contribuinte) e as suas necessidades, manter com ele um canal de relacionamento, tomar decisões baseadas em fatos etc. Isso ajuda a preservar os principais serviços acessíveis à população que deles necessita, pois essa acessibilidade pode variar ao longo do tempo, com o crescimento da cidade, bem como com as alterações no uso e ocupação do solo e planos de transporte e circulação. A acessibilidade deve ser avaliada tomando-se como referência os equipamentos públicos, tais como: escolas, delegacias, serviços, hospitais, prontos-socorros etc. Assim, este trabalho propõe um procedimento metodológico para conhecer melhor os usuários e avaliar a acessibilidade a equipamentos públicos.
Nesse caso, será tomado como exemplo um tipo de equipamento público relacionado com a área de saúde, ou seja, hospitais do tipo "Santa Casa".

$\mathrm{Na}$ gestão pública, nos diversos níveis, principalmente na esfera municipal, tem-se feito uso de ferramentas computacionais, como é o caso de Sistemas de Informações Geográficas (SIG), capazes de produzir resultados importantes na tomada de decisão pelo poder público, bem como ser facilmente entendíveis pelo cidadão mais leigo. Na área de saúde pública o SIG tem sido usado de forma recorrente, pois nesse tipo de software a distribuição espacial é feita através de uma base de dados gráficos, que pode ser construída e utilizada para realizar associações entre as ocorrências de doenças e o meio ambiente físico/antrópico (Johnson \& Johnson, 2001; Gotz et al., 2009; Rabelo et al., 2013).

Em vista disso, este trabalho tem como principais objetivos: i) desenvolver um procedimento metodológico para avaliação de acessibilidade a equipamentos públicos; ii) caracterizar as viagens aos hospitais - social e espacialmente - para conhecimento das características de seus usuários; iii) calcular os níveis de acessibilidade aos hospitais, considerando os modos de transporte a pé, automóvel e transporte público coletivo, a partir de setores censitários; iv) mostrar a importância do uso de SIG na gestão urbana. Espera-se com os resultados poder contribuir para uma melhor gestão urbana, principalmente do transporte público urbano.

\section{Polos Geradores de Viagens}

Polos Geradores de Viagens (PGV) são equipamentos potenciais geradores de impactos nos sistemas viário e de transportes, como também no desenvolvimento socioeconômico e qualidade de vida da população (Portugal, 2012). Muitos são os estabelecimentos considerados como PGVs: shopping centers, centros de estudos (universidades, escolas), centros de saúde (hospitais, prontos-socorros, clínicas, laboratórios, postos de saúde), estádios, estações de transportes públicos etc.

0 estabelecimento de empreendimentos geradores de viagens sem um adequado estudo de seus impactos aumenta a gravidade dos problemas já existentes nas cidades, pois estes podem causar um crescimento desordenado, devido à falta de processo 
integrado de planejamento urbano e de transportes. A construção desse tipo de empreendimento pode causar vários impactos, inclusive na qualidade de vida da população. Em contrapartida, quando bem localizados e projetados, podem estimular a adoção de políticas de gerenciamento da demanda de viagens para promover uma mobilidade mais sustentável; fortalecer a centralidade local, valorizando e desenvolvendo a região na qual se inserem (Portugal, 2012; Raia et al., 2008).

O Estatuto da Cidade (Lei n. 10.257/2001) prevê a elaboração de planos de transporte integrados apenas para cidades de grande porte, com população acima de 500 mil habitantes (Oliveira, 2001). Outrossim, o Estatuto da Mobilidade (Lei n. 12.587/2012) obriga que os municípios acima de 20 mil habitantes se adequem às normas por ele estabelecidas em até três anos. Dentre as inúmeras diretrizes apontadas, podem-se citar: integração com a política de desenvolvimento urbano e respectivas políticas setoriais de habitação, planejamento e gestão do uso do solo nos âmbitos dos entes federativos; integração entre os modos e serviços de transporte urbano; priorização de projetos de transporte público coletivo estruturadores do território e indutores do desenvolvimento urbano integrado (Brasil, 2012).

Ao contrário dos empreendimentos voltados ao lazer, consumo e estudos, os PGV do tipo estabelecimentos de saúde seguem uma lógica diferente, pois são voltados para a necessidade dos cidadãos por um determinado período. Não geram viagens espontâneas, e sim por necessidade, tais como consultas médicas, exames, internações etc. Além disso, a implementação e localização desses PGV nos municípios, na maioria das vezes, não seguem a regra mercadológica dos outros empreendimentos.

Um empreendimento hospitalar pode ser considerado um Polo Gerador de Viagem devido à sua relevância social, econômica e modo particular de funcionamento, pois operam 24 horas por dia e 365 dias por ano. Segundo Toledo \& Demajorovic (2006, p. 7), "os hospitais executam funções muitas vezes semelhantes àquelas encontradas na indústria, tais como lavanderia, transporte, limpeza, alimentação", dentre outras. Além disso, descartam grandes quantidades de lixo hospitalar, que exigem cuidados especiais para seu manuseio e destinação.

Mesmo sem terem a intenção de se tornar novos centros, como no caso de shopping centers, os hospitais acabam atraindo para o seu entorno empreendimentos com características semelhantes às suas atividades, tais como clínicas médicas e laboratórios. Atraem também outras atividades não relacionadas à área da saúde ou pertinentes: restaurantes, hotéis, lanchonetes, estacionamentos etc. Portanto, acabam possuindo características semelhantes às de um polo local de atividades, pelo fato de atrair um grande número de viagens, além daquelas já atraídas pelo empreendimento hospitalar.

\section{Acessibilidade a hospitais}

No caso dos hospitais públicos, objeto deste estudo, muitos deles foram projetados e localizados em épocas em que, possivelmente, o aspecto da acessibilidade não fosse tão significativo como nos dias atuais, pelo próprio tamanho das cidades e/ou políticas urbanas. Evidentemente que neste estudo não se cogita a transferência desses estabelecimentos para regiões mais acessíveis ao público usuário. Mas na proposição de um processo de gestão de saúde, em que se podem confirmar (ou não) possíveis ineficiências na acessibilidade de grupos de pessoas menos privilegiadas financeiramente. Como consequência, pode-se sugerir modificações nos sistemas de transportes, principalmente em relação a essas regiões, com vistas a aumentar a qualidade de vida urbana. No Brasil, a acessibilidade relacionada a equipamentos públicos, em particular aos da área de saúde, tem merecido pouca atenção. $\mathrm{Na}$ literatura encontram-se ainda poucos estudos a respeito (Freire et al., 2008; Urbe Planejamento, 2013; Garcia \& Raia, 2011; Garcia, 2012; Ferreira \& Raffo, 2013).

Em nível internacional, há maior preocupação com o tema. Dentre as experiências de avaliação sobre a acessibilidade no exterior, destaca-se o condado de Worcestershire, Reino Unido. Reconhece que a manutenção e melhoria da acessibilidade aos serviços e equipamentos urbanos são importantes para influenciar a forma como as pessoas viajam, a sua qualidade de vida e sua participação na sociedade. Os problemas resultantes de uma baixa acessibilidade aos principais serviços e instalações são reais, dentre eles os hospitais. Em um período de 12 meses, alvo da pesquisa, 1,4 milhão de pessoas deixaram, diminuíram ou optaram por não procurar 
ajuda médica por causa de problemas de transporte. Apenas 36\% da população no Reino Unido têm acesso a hospitais por meio de transportes públicos, a pé ou de bicicleta (Worcestershire County Council, 2011). 0 condado de Worcestershire (560 mil habitantes) teve como objetivo que, em $2011,84 \%$ da sua população alcançassem uma acessibilidade de até 60 minutos de viagem por ônibus aos hospitais locais.

Destaca-se, também, o estudo detalhado sobre a acessibilidade a hospitais no condado de Worcestershire (Worcestershire County Council, 2010). No estudo, os autores deixam claro que o investimento no modal automóvel traz muitas desvantagens para os locais onde estão implantados os hospitais. Defendem investimentos mais sustentáveis para melhorar a acessibilidade por meio de modos de transportes mais sustentáveis como são os casos do transporte público coletivo, a pé e por bicicleta.

Estudos sobre acessibilidade a equipamentos públicos foram realizados na cidade de Dublin, Irlanda, onde foi utilizado o índice de acessibilidade de distância aos empreendimentos (Gamma \& Haaze, 2007).

\section{Metodologia}

A realização deste trabalho constou das seguintes etapas relacionadas aos procedimentos metodológicos: 1a Etapa - Planejamento e coleta das informações; 2a Etapa - Construção da base digital; e 3므 Etapa - Obtenção dos indicadores de acessibilidade e análise dos resultados.

A 1 1 Etapa (Planejamento e coleta das informações) está dividida em duas partes: planejamento da pesquisa de campo e coleta das informações. A fase de planejamento da pesquisa de campo consiste na escolha dos objetos de estudo (cidades de porte semelhantes que possuam unidades hospitalares que atendam pelo SUS) e na elaboração do questionário aplicado, em campo, junto aos usuários desses equipamentos públicos. Os ajustes e correções do questionário foram realizados após a pesquisa piloto (aplicada em um dos objetos de estudo), na qual se puderam identificar as possíveis falhas. Após a escolha dos objetos de estudo, solicitou-se a cada empreendimento hospitalar uma autorização para a realização da pesquisa e encaminhou-se um formulário para obtenção de informações sobre o empreendimento, tais como: identificação do empreendimento; dados físicos e operacionais (quantidade de pacientes, estimativa do número diário de visitantes, quantidade de leitos, quadro de dias e horários de visita); dados sobre possíveis unidades hospitalares (maternidade, prontosocorro, ambulatório etc.); dados a respeito do nível de complexidade hospitalar (baixo, médio ou alto); e percentual de atendimentos realizados pelo SUS. Essas informações foram de fundamental importância para o planejamento da pesquisa de campo, pois em se tratando de um estudo em um empreendimento desse porte é importante que se conheça bem a dinâmica de seu funcionamento.

A coleta das informações em campo foi realizada através da contagem volumétrica de pessoas que acessaram o hospital (independente do motivo) durante uma semana, de $2^{\underline{a}}$ a $6^{\underline{a}}$ feira, das $6 \mathrm{~h}$ às $18 \mathrm{~h}$, para cada empreendimento, para uma "semana tipo". Foram evitadas as semanas com feriados e datas próximas às férias escolares. Identificado o dia de maior volume semanal (dia pico), aplicouse um questionário do tipo entrevista estruturada aos usuários dos empreendimentos hospitalares. Segundo Boni \& Quaresma (2005, p. 73), "as entrevistas estruturadas são elaboradas mediante questionário totalmente estruturado, ou seja, é aquele onde as perguntas são previamente formuladas e tem-se o cuidado de não fugir a elas". O questionário final continha as seguintes informações: perfil do usuário (idade); motivo da ida ao hospital (paciente, visitante, acompanhante, funcionário, prestador de serviço); modo de transporte utilizado (automóvel, ônibus, motocicleta, a pé, bicicleta, outros); cidade de residência do usuário; caso residente, a origem do usuário (endereço da residência).

Os dados identificados como necessários a este trabalho foram pesquisados nas seguintes instituições: IBGE (dados cartográficos e censitários), Dieese, prefeituras municipais das cidades em estudo, dentre outras.

A 2 ${ }^{\text {a }}$ Etapa (Construção da base digital) consiste na construção da base digital de cada uma das cidades, através da elaboração dos mapas das redes (caso não estivesse disponível em base digital) e da espacialização dos pontos de origem das viagens dos usuários aos hospitais. Foram necessários os seguintes dados e materiais: dados do trabalho de campo compilados e mapas digitais (sistema 
viário, setores censitários etc.). Todos esses dados são importantes para que se possa trabalhar em um software de SIG (Sistemas de Informações Geográficas), que possui ferramentas que auxiliam no processo de análises dos resultados de estudos de redes.

Na 3a Etapa (Obtenção dos indicadores de acessibilidade e análise dos resultados) foi definido o indicador de acessibilidade a ser estudado para cada uma das zonas censitárias, no caso, o indicador tempo de viagem. Por se tratar de uma análise feita segundo os modos de transporte, é desejável o uso de indicadores do tipo separação espacial, bem como da sua disponibilidade, por isso a escolha do indicador tempo de viagem. Cada setor censitário foi classificado segundo o rendimento médio familiar disponível no censo populacional. Para as análises foram considerados os modos de transporte: a pé, automóvel e transporte público coletivo por ônibus, que são, em geral, os mais utilizados. 0 tratamento de todos esses dados foi realizado em ambiente SIG. Para as análises das viagens a pé e automóvel através da variável tempo de viagem, utilizou-se o sistema viário (arquivo de rede) como referência. Para as análises das viagens por transporte público coletivo, além do sistema viário foram considerados também dados das linhas em operação nas cidades em estudo na época da pesquisa.

\section{Aplicação do método e resultados}

Para facilitar a compreensão da aplicação da metodologia, dividiu-se esta seção em duas partes: i) Pesquisa de campo, etapa pela qual se abordam os dados obtidos em campo; e ii) Avaliação da acessibilidade, etapa em que se estima o tempo médio de viagem dos setores censitários ao hospital de cada cidade, além da identificação dos setores com maior número de usuários e suas respectivas análises.

\section{Objetos de estudo}

Os objetos de estudo do presente trabalho foram dois hospitais do tipo "Santa Casa", localizados nas cidades médias paulistas de Rio Claro e São Carlos. A escolha foi feita em função das características semelhantes entre os hospitais, pois esses tipos de empreendimentos dificilmente possuem padrões semelhantes, e a oferta de especialidades pode variar significativamente entre eles.

Rio Claro, município localizado na região central do estado de São Paulo, a $173 \mathrm{~km}$ da capital, conta com uma população de 186.253 habitantes (IBGE, 2012). 0 estudo foi realizado no Hospital Santa Casa Saúde, que é o único hospital público do município. 0 percentual de atendimentos na unidade que são realizados pelo SUS é de 77,7\% (de acordo com a administração do hospital), possui 167 leitos e oferece tratamento de alta e média complexidades principalmente dos seguintes serviços: Oncologia, Nefrologia, Hematologia e Cardiologia. Atende a população da microrregião de Rio Claro, que compreende também os municípios de Analândia, Corumbataí, Ipeúna, Itirapina e Santa Gertrudes.

0 município de São Carlos localiza-se no centro geográfico do estado de São Paulo, a $240 \mathrm{~km}$ da capital, com uma população de 221.950 habitantes (IBGE, 2012). 0 objeto de estudo é a Santa Casa de Misericórdia e na data da pesquisa (2010) era o único hospital público da cidade. Existem três prontos-socorros na cidade e o Hospital-Escola, que não se encontrava em pleno funcionamento na época da pesquisa. A Santa Casa possui 337 leitos e $70 \%$ dos atendimentos realizados na unidade hospitalar são através do SUS. Oferece tratamento de alta complexidade, principalmente nos serviços de Nefrologia, Cardiologia, Radioterapia, Ortopedia, UTI Neonatal, Gestação Alto Risco.

\section{Pesquisa de campo}

Através da contagem volumétrica (número de pessoas), identificou-se o dia pico, que em São Carlos foi a $2^{\underline{a}}$ feira e, em Rio Claro, a $4^{\underline{a}}$ feira. Nos dias pico específicos de cada equipamento público, e na semana posterior à contagem volumétrica, aplicouse o questionário aos usuários de cada Santa Casa. A amostra foi calculada estatisticamente em função do volume de pessoas que acessaram os hospitais nos dias pico. Porém, de toda a amostra obtida, foram considerados apenas os questionários com os dados da população usuária, não envolvendo médicos, funcionários e prestadores de serviços. Além disso, alguns questionários não foram aproveitados por apresentarem dados insuficientes ou inexistentes 
sobre a localização de origens. Assim, utilizaram-se 254 questionários em Rio Claro e 322 em São Carlos. E, desses, 16,5\% (Rio Claro) e 7,5\% (São Carlos) foram de usuários "não residentes".

Na Tabela 1 estão a distribuição etária obtida em campo e os dados segundo o Censo 2010 (IBGE, 2012), relativos a cada cidade, de forma a comparar a distribuição da população (por faixa etária) com a população usuária do hospital. 0 confronto entre esses dados revelou grandes semelhanças entre as porcentagens nas faixas etárias de usuários de ambos os empreendimentos e também algumas semelhanças com os dados do Censo 2010 (IBGE, 2012).

De acordo com o Censo 2010 (IBGE, 2012), a faixa etária entre 25 e 45 anos representa, individualmente, a maior parcela da população, em ambos os objetos de estudo, segundo a pirâmide de distribuição da população, segundo os grupos de idade. Dessa forma, fica caracterizada uma semelhança entre a quantidade de pessoas na pirâmide com o número de viagens realizadas. Na pesquisa de campo, essa faixa etária também foi a mais representativa, pois é a parcela da população que mais utilizou os serviços hospitalares no dia da coleta de dados em ambas as cidades. A faixa etária de 45 a 60 anos é a terceira maior parcela da população segundo o Censo. Essa parcela da população foi a segunda maior encontrada na população usuária dos empreendimentos hospitalares. A população que se encontra na faixa etária acima de 60 anos representa a quarta maior população (IBGE, 2012), em ambos os municípios. Os dados encontrados pela pesquisa de campo mostram que essa faixa da população é a terceira maior parcela de população usuária dos hospitais.

Em relação ao modo de transporte usado pelos entrevistados, foram considerados, separadamente, os dados de usuários - "residentes" e "usuários não residentes", ou seja, aqueles que moram nas cidades objeto de estudo e aqueles que moram em outras cidades da região e precisam realizar uma viagem intermunicipal para ter acesso ao serviço. A distribuição modal das viagens no município é um dado que não se encontra disponível, assim os resultados analisados são baseados nos dados coletados em campo.

No caso dos usuários residentes em São Carlos, $59,2 \%$ realizaram suas viagens ao hospital por automóvel; em Rio Claro, a porcentagem foi de 41,5\%. Aqueles que fizeram uso de transporte coletivo apresentaram valores de 27,8\% (São Carlos/SP) e 18,4\% (Rio Claro/SP). Em relação às viagens a pé, em Rio Claro o valor obtido foi de 5,7\% e, em São Carlos, 3,7\%. 0 modo de transporte denominado "outros modos" (ambulâncias, vans de prefeituras etc.) representou $12,7 \%$ das viagens realizadas em Rio Claro e 3,3\%, em São Carlos. Por fim, 12,3\% das viagens foram feitas por motocicleta em Rio Claro e 5,7\%, em São Carlos. É importante destacar que, em Rio Claro, 9,4\% das respostas obtidas foram de usuários que utilizaram a bicicleta como meio de transporte ao hospital, sendo que, em São Carlos, apenas $0,5 \%$ dos entrevistados declarou ter usado esse meio de transporte.

Em relação aos usuários "não residentes", também há a prevalência do uso do automóvel, em ambas as cidades: $57,2 \%$ em Rio Claro e $66,7 \%$ em São Carlos. A segunda alternativa mais usada foi "outros modos", que em Rio Claro representou $30,9 \%$ das viagens, enquanto que, em São Carlos, $12,5 \%$. As viagens realizadas por ônibus intermunicipais corresponderam a 20,8\% do total das viagens, em São Carlos, e 11,9\%, em Rio Claro. Para os usuários "não residentes", os hospitais são considerados como uma referência microrregional, porém não concorrentes entre si.

Tabela 1 - Comparaçã̃o da distribuição da população (\%) dos municípios por faixa etária do Censo 2010/IBGE e dos dados obtidos em campo

\begin{tabular}{|c|c|c|c|c|c|c|c|c|c|c|}
\hline \multirow{3}{*}{ Município } & \multicolumn{10}{|c|}{ Faixa etária } \\
\hline & \multicolumn{2}{|c|}{ Até 18 anos } & \multicolumn{2}{|c|}{$19-25$ anos } & \multicolumn{2}{|c|}{ 25-45 anos } & \multicolumn{2}{|c|}{ 45-60 anos } & \multicolumn{2}{|c|}{ Mais de 60 anos } \\
\hline & IBGE & Campo & IBGE & Campo & IBGE & Campo & IBGE & Campo & IBGE & Campo \\
\hline Rio Claro & 25,94 & 1,89 & 10,25 & 11,32 & 32,51 & 42,92 & 18,10 & 25,47 & 13,20 & 18,40 \\
\hline São Carlos & 25,56 & 1,55 & 10,23 & 11,49 & 32,81 & 45,03 & 18,49 & 22,36 & 12,91 & 19,57 \\
\hline
\end{tabular}

Fonte: Adaptado de IBGE (2012). 


\section{Avaliação da acessibilidade}

Para essa etapa, utilizaram-se os dados obtidos através dos questionários aplicados nas entrevistas, os mapas dos sistemas viários georreferenciados das duas cidades e mapas georreferenciados dos setores censitários do IBGE, atualizados de acordo com o Censo 2010. Adotou-se, como medida de avaliação da acessibilidade, o tempo de viagem desde a origem (hipoteticamente considerado como sendo os centroides dos setores censitários) até o destino final (hospital), para cada modo de transporte considerado. 0 cálculo do tempo de viagem foi feito utilizando-se um software de SIG (TransCAD), que possui ferramentas apropriadas para análise em transportes.

Para as viagens por automóvel e transporte público coletivo, utilizou-se como referência a velocidade regulamentada das vias de cada cidade. Para as viagens a pé, adotou-se o valor de $4,8 \mathrm{~km} / \mathrm{h}$ (Grava, 2004) como velocidade média de caminhada.

Diversos equipamentos públicos (escolas, creches, postos de saúde etc.) atendem determinadas regiões da cidade. Já os hospitais públicos que atendem prioritariamente os pacientes do SUS, principalmente, em cidades pequenas e médias, são em quantidade pequena; em grande parte das cidades, como é o caso aqui tratado, há um único equipamento disponível.

\section{Cálculo da acessibilidade pelo modo a pé}

As viagens realizadas aos hospitais pelo modo a pé apresentaram valores de 5,7\% (Rio Claro/SP) e 3,7\% (São Carlos/SP). As duas cidades em estudo possuem diferentes características de relevo. Enquanto São Carlos apresenta uma variação acentuada na topografia, Rio Claro, ao contrário, se encontra em uma região plana, o que facilita as viagens a pé e por bicicleta.

Através das análises do tempo de viagem a pé, elaboradas com o software (TransCAD), identificaram-se alguns usuários originários de regiões de até 20 minutos de caminhada em ambas as cidades. Porém, muitos outros são originários de regiões com distâncias superiores a $4 \mathrm{~km}$ dos hospitais. Em se tratando de uma cidade de topografia plana pode não ser uma distância tão expressiva, mas em uma cidade de topografia acidentada, e até mesmo em situações de urgência, é uma distância significativamente alta para se realizar a pé. Para ilustrar, as Figuras 1 e 2 contêm mapas temáticos com os tempos de viagem a pé, considerando-se um raio de 1,5 km em relação ao hospital.

As áreas dos setores censitários foram associadas às origens das viagens dos usuários aos hospitais, podendo-se, assim, obter-se o total de viagens iniciadas em cada setor censitário. A Figura 1 contém o mapa de Rio Claro com os setores censitários em destaque e os bairros mais próximos a eles (ex.: Zona Central, Recanto Paraíso e Oficina Fepasa). Os setores censitários com maior número de usuários em São Carlos estão destacados na Figura 2, bem como os bairros mais próximos a eles (ex.: Centro, Vila Costa do Sol, Jardim Brasil).

\section{Cálculo da acessibilidade pelo modo automóvel}

Para determinar a acessibilidade através do indicador tempo de viagem por automóvel utilizou-se a velocidade regulamentada para os diversos trechos das vias, sem, no entanto, contabilizar o tempo de parada em semáforos e/ou cruzamentos, pois esses dados não estavam disponíveis e não haveria tempo hábil para coletá-los em campo e utilizá-los nesta pesquisa.

0 automóvel foi o meio de transporte mais utilizado nas viagens realizadas aos hospitais, tanto em Rio Claro (41,5\%) quanto em São Carlos (59,2\%). Em grande parte dos casos, as viagens são realizadas em situações de urgência/emergência, fazendo-se uso de automóveis, quando não há a necessidade de uma ambulância, pois esse veículo realiza as viagens em menor tempo do que outros meios de transportes. Mas há também viagens por motivos de visitas, consultas etc. Por se tratar de cidades de médio porte, as distâncias médias de viagem por automóvel, em cada uma delas, apresentaram valores relativamente baixos. Poucas foram as zonas que apresentaram viagens com tempo médio acima de 15 minutos.

Para ilustrar a localização de algumas zonas censitárias que continham maior número de usuários, selecionaram-se sete delas para cada uma das cidades, como mostram as Figuras 3 e 4, respectivamente, para Rio Claro e São Carlos. Em todas as zonas censitárias citadas, o percentual 


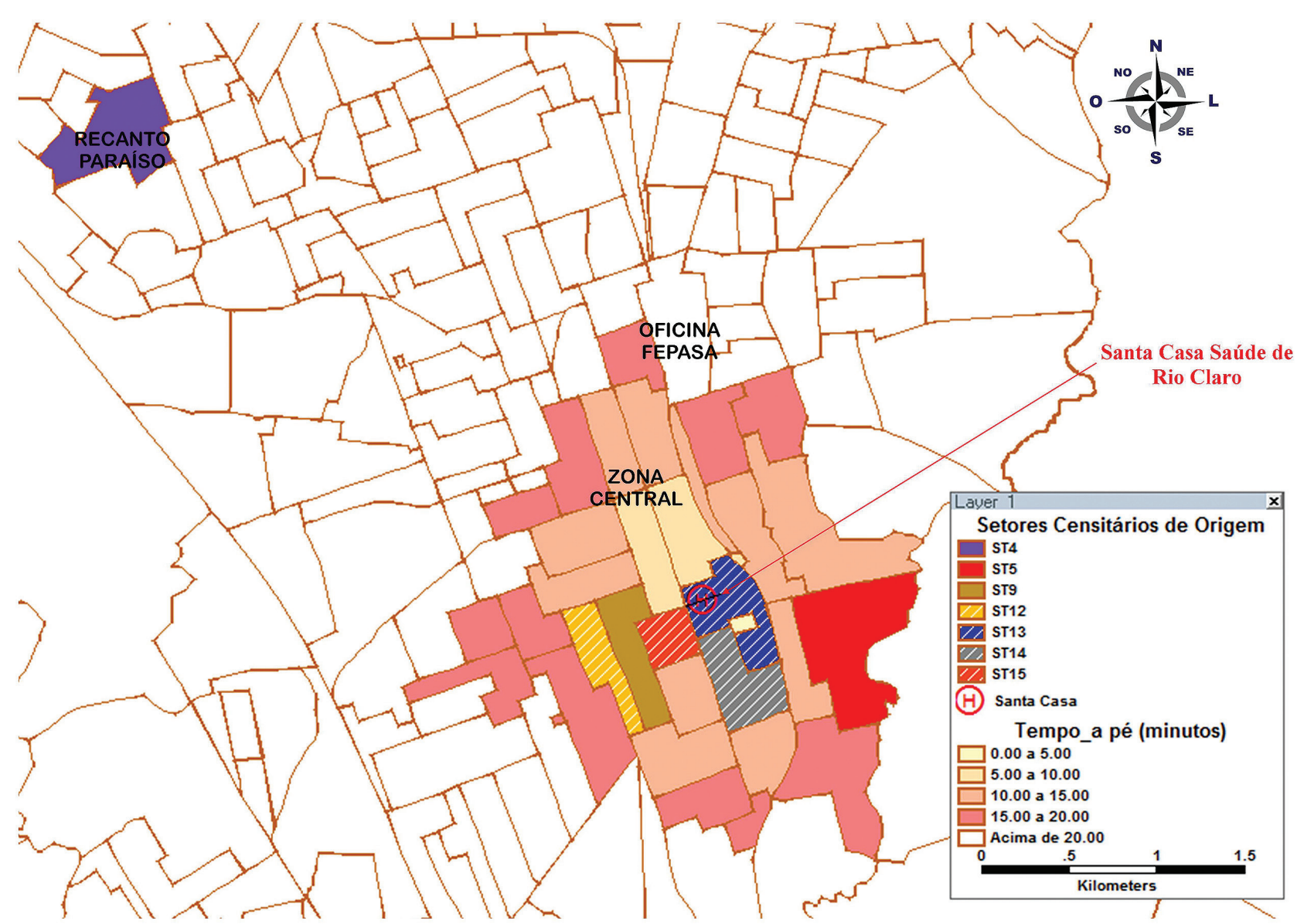

Figura 1 - Setores censitários de origem da maioria das viagens a pé em Rio Claro Fonte: Garcia (2012).

de usuários viajantes apresentou valores abaixo de $4 \%$, o que pode indicar que não existe uma concentração de usuários em apenas uma ou poucas regiões da cidade. Isso mostra a importância da localização dos hospitais em estudo em relação aos serviços por eles prestados. Fica evidenciada a necessidade de planejamento e gestão da mobilidade a esses equipamentos de saúde, tais como: vagas de estacionamentos em quantidades adequadas, disponibilidade de linhas de transporte coletivo de forma suficiente e com menores tempos de espera nos pontos etc.

Cálculo da acessibilidade pelo modo transporte público coletivo (ônibus)

Para a avaliação da acessibilidade através do tempo de viagem por transporte público coletivo, digitalizaram-se, no software de SIG, os trajetos das diversas linhas que compõem o sistema de transporte público, obtidos a partir da descrição analítica das rotas de cada uma das cidades. Foram necessários, adicionalmente, dados do intervalo de tempo entre veículos sucessivos de cada linha (headway). A localização georreferenciada dos pontos de parada também seria importante para a utilização de ferramenta específica para o cálculo do tempo de viagem, usando-se o SIG. No entanto, como esse dado não estava disponível, optou-se pela utilização de uma análise mais simplificada, feita com base no sistema viário, utilizado pelas rotas do ônibus.

Outra simplificação foi necessária. Por hipótese, adotou-se que as origens das viagens ocorriam a partir do centroide de cada zona censitária. Esse recurso tem sido recorrentemente usado em estudos de planejamento de transportes, como no caso de Mowforth (1989) e Zhen \& Zhang (2012), dentre outros. Dessa maneira, para determinar o tempo de viagem pelo transporte público coletivo (TPC), desde 


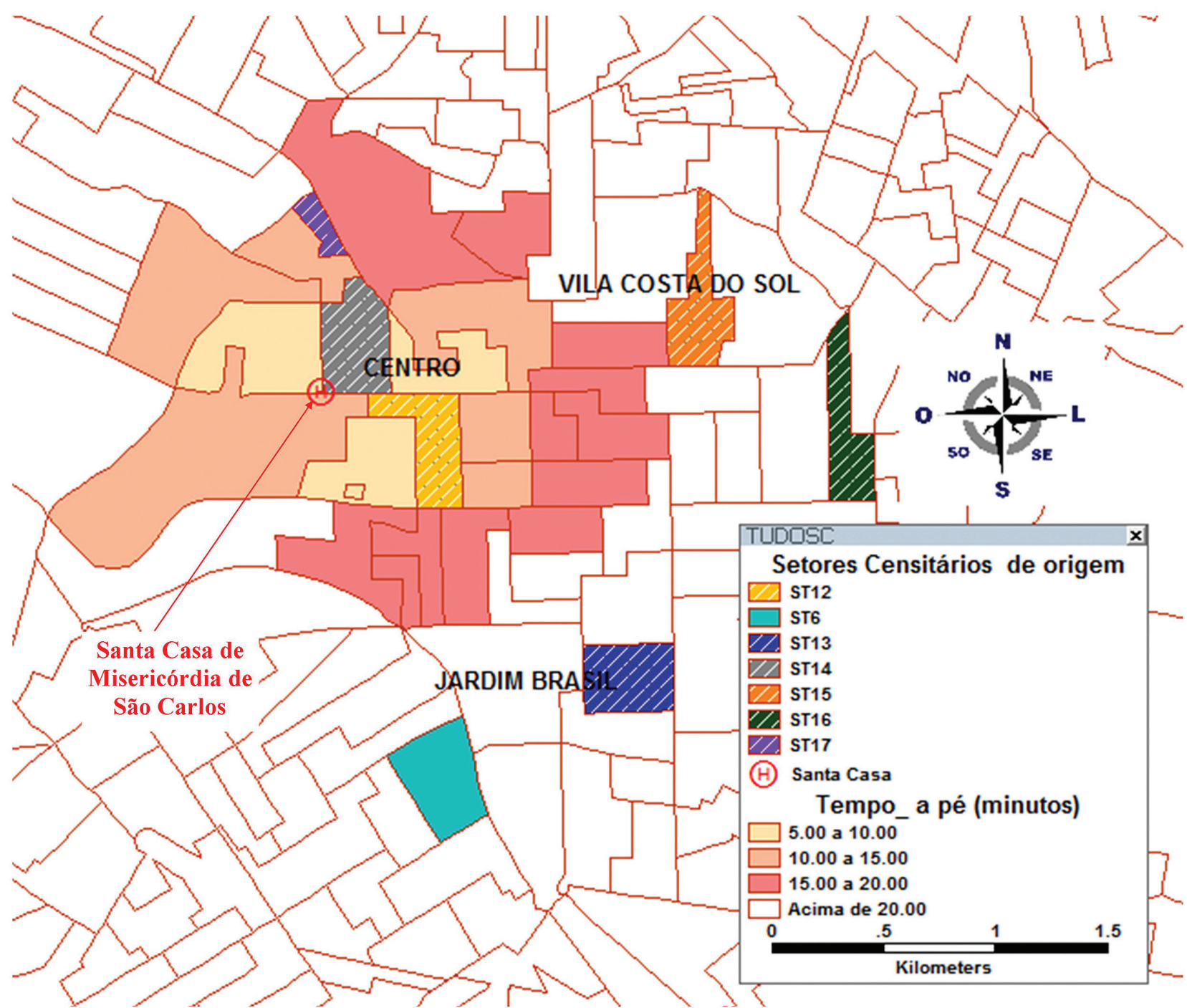

Figura 2 - Setores censitários de origem da maioria das viagens a pé em São Carlos

Fonte: Garcia (2012).

a origem até o hospital, foi necessário considerar algumas variáveis: tempo de viagem a pé (linhas que ligam cada centroide ao sistema viário por onde o TPC passa) e tempo de percurso do transporte coletivo nas vias, considerando-se velocidade média do TPC de 22,5 km/h (Costa, 2008).

Para efeito de cálculo, utilizou-se a ferramenta matriz de caminhos múltiplos do SIG, que considera os trechos de viagens a pé e no interior do veículo. Adicionalmente, estimou-se o tempo médio de espera $\left(\mathrm{T}_{\mathrm{m}}\right)$ pelo passageiro pela passagem de dois veículos subsequentes no ponto de ônibus. No cálculo do $\mathrm{T}_{\mathrm{m}}$ incluíram-se todas as linhas pelo fato de que o usuário pode fazer o transbordo de uma linha para outra, caso não tenha uma que ofereça acesso direto.
0 tempo médio de espera $\mathrm{T}_{\mathrm{m}}$ de uma mesma linha ou não, considerando aquelas que passam no entorno do hospital, é dado pela Equação 1.

$T_{m}=\frac{a}{100} \cdot \frac{\bar{h}_{a}}{2}+\frac{b}{100} \cdot \frac{\bar{h}_{b}}{2}$

em que $a$ é o percentual de linhas que passam pelo hospital; $\bar{h}_{a}$ é o headway médio de todas as linhas que passam pelo hospital; $b$ é o percentual de linhas que não passam pelo hospital; $\bar{h}_{b}$ é o headway médio de todas as linhas que não passam pelo hospital. 0 cálculo do headway médio de cada grupo de linhas $i$ (as que passam pelo hospital e as que não passam pelo hospital) é dado pela somatória do headway (h) 


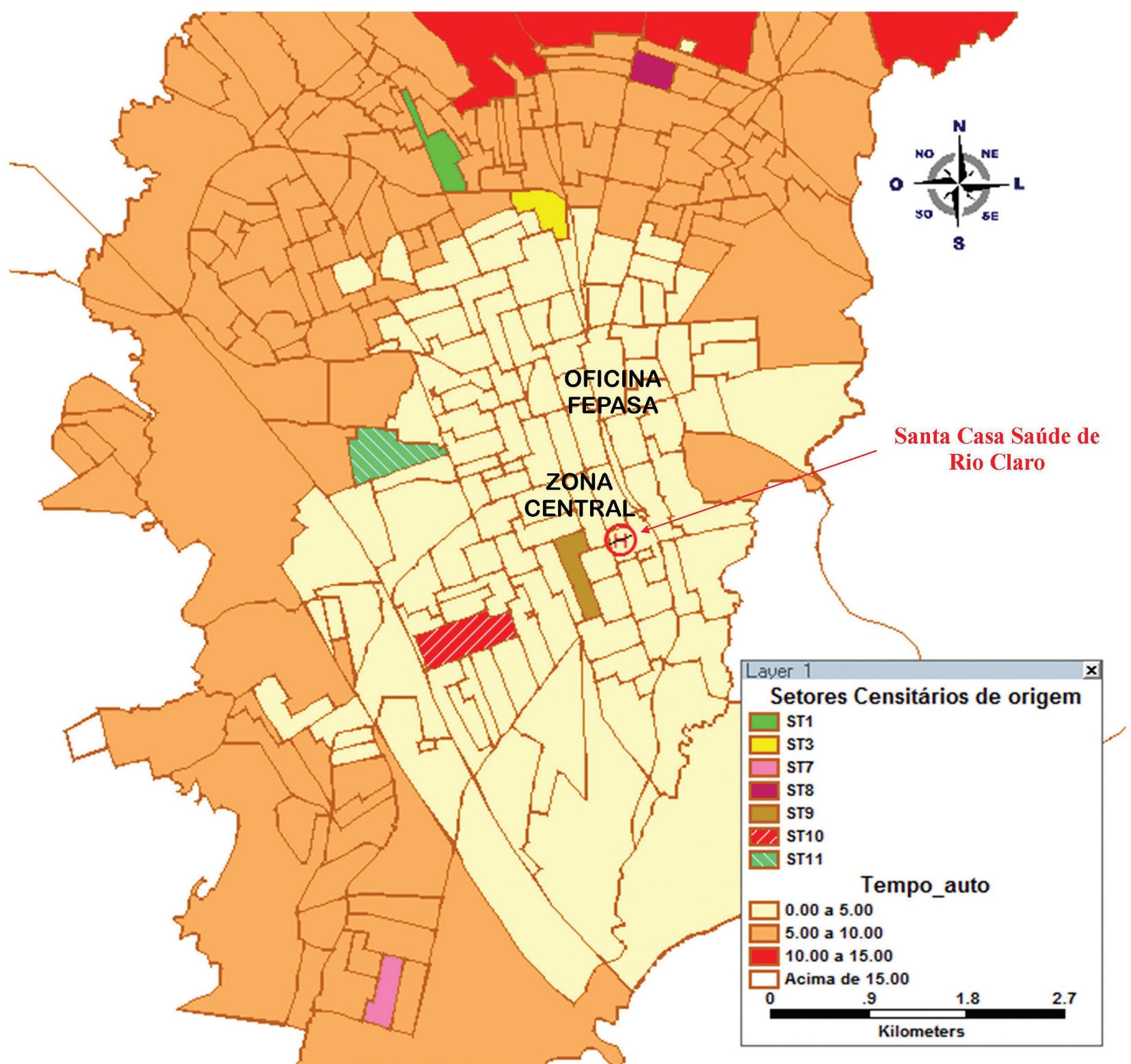

Figura 3 - Localizaccão das zonas de origem das viagens por automóvel em Rio Claro Fonte: Garcia (2012).

de cada uma delas dividido pelo número de linhas de cada grupo (n), conforme Equação 2.

$\overline{h_{i}}=\frac{\sum_{i=1}^{n} h_{i}}{n_{i}}$

Em Rio Claro, apenas uma linha de transporte coletivo passava pela Avenida Quinze, via onde está localizada a entrada principal da Santa Casa. As demais linhas de transporte coletivo passavam pela Rua Um, localizada perpendicularmente à Avenida Quinze. A cidade tinha disponível, em março de 2012, 21 linhas de transporte coletivo, sendo que 10 delas atendiam a região onde está localizada a Santa Casa (passavam ao redor do quarteirão), o que equivale a $47,6 \%$ do total de linhas de transporte coletivo disponíveis na cidade. 0 tempo médio de espera $\left(\mathrm{T}_{\mathrm{m}}\right)$, calculado conforme Equação 1, foi de 23 minutos. Em Rio Claro, todas as linhas passam pelo Terminal Central, onde as pessoas podem acessar outra linha, caso seja necessário fazer transbordo.

Em São Carlos, 19 linhas de transporte coletivo passavam ao redor do quarteirão da Santa Casa (dados de março de 2012), que tem acessos pelas ruas Maestro João Sepe e Paulino Botelho de Abreu 


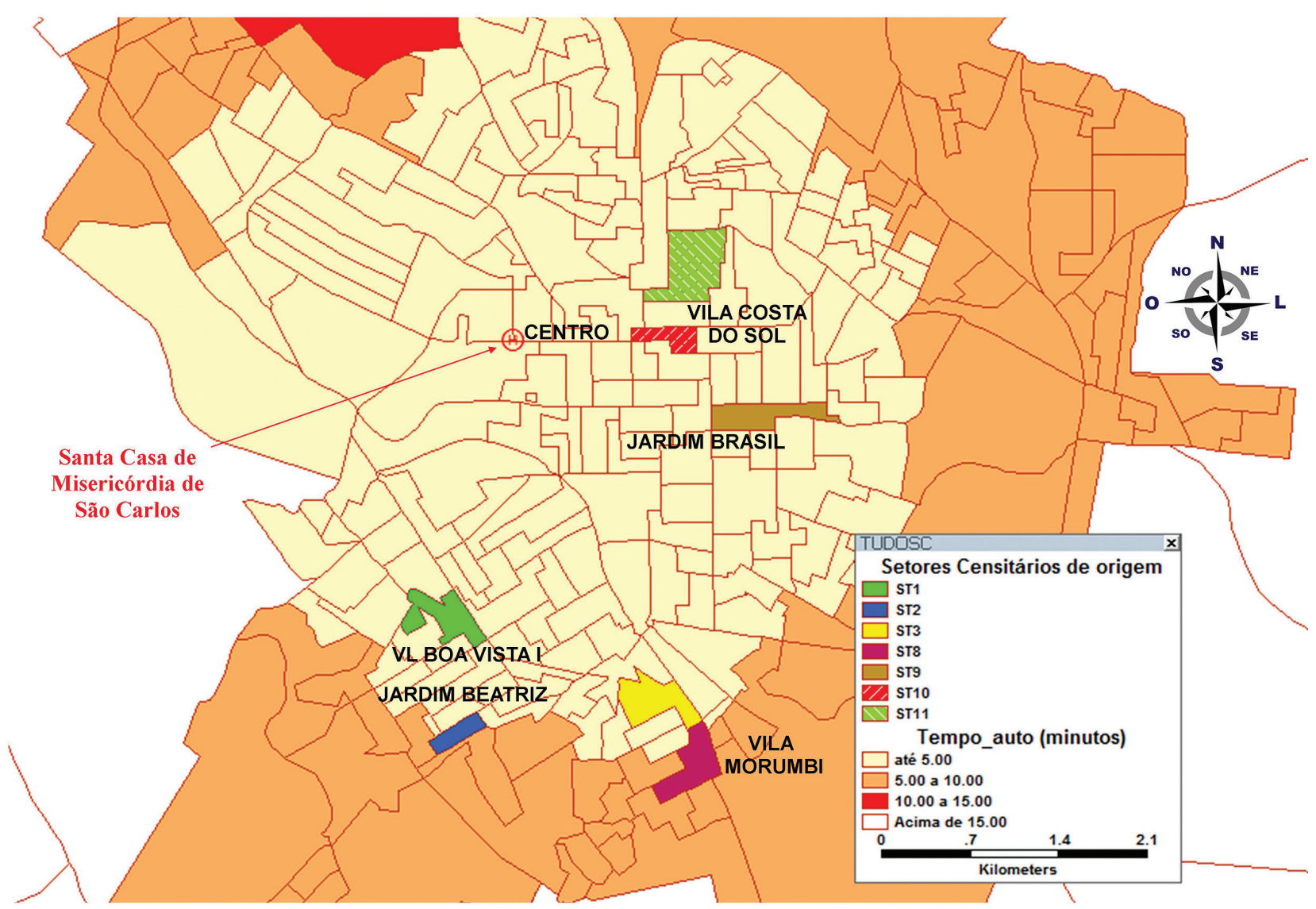

Figura 4 - Localização das zonas de origem das viagens por automóvel em Sc̃o Carlos Fonte: Garcia (2012).

Sampaio, onde se localiza a sua entrada principal. A cidade tem à disposição 61 linhas diurnas principais de transporte coletivo (fora as linhas noturnas e especiais) e 31,1\% destas atendem a região onde está localizada a Santa Casa. 0 tempo médio de espera calculado foi de 30 minutos. A zona central, por ser abastecida por uma quantidade maior de linhas em relação às áreas periféricas, acaba se tornando uma região com maior acessibilidade ao hospital. Em São Carlos, o sistema de transporte coletivo é do tipo integrado, ou seja, se a pessoa precisar fazer transbordo em algum ponto da cidade para ir a um determinado destino, a tarifa a ser paga é única, se ela acessar essa segunda linha em um período de tempo predeterminado.

Comparando-se as duas cidades, em relação ao percentual de linhas existentes em cada uma, em São Carlos 31,1\% atendem a região hospitalar diretamente; em Rio Claro, 47,6\%. Entretanto, considerando-se em números absolutos, a quantidade de linhas de TPC que atendem o hospital em São
Carlos é quase o dobro da existente em Rio Claro. Isso mostra que, em muitos casos, deve-se avaliar não apenas o percentual encontrado, mas a quantidade de linhas e horários que, em números absolutos, uma região é atendida. Assim, em São Carlos, a Santa Casa é beneficiada pela grande quantidade de linhas que passam próximas ao empreendimento, o que facilita ainda mais o acesso da população aos seus serviços. Talvez seja por isso que a quantidade de usuários do TPC em São Carlos tenha apresentado um valor maior $(27,7 \%)$ em comparação com o valor de Rio Claro (18,4\%).

Os mapas das Figuras 5 e 6 foram elaborados através dos dados obtidos para os tempos de viagem, calculados pelo software, mais o acréscimo do tempo médio de espera, calculado em função do headway das linhas que servem a cada setor censitário (Equação 2).

Em se tratando da necessidade de atendimentos urgentes, como são os casos de grande parte das viagens aos hospitais, os valores de tempo total 


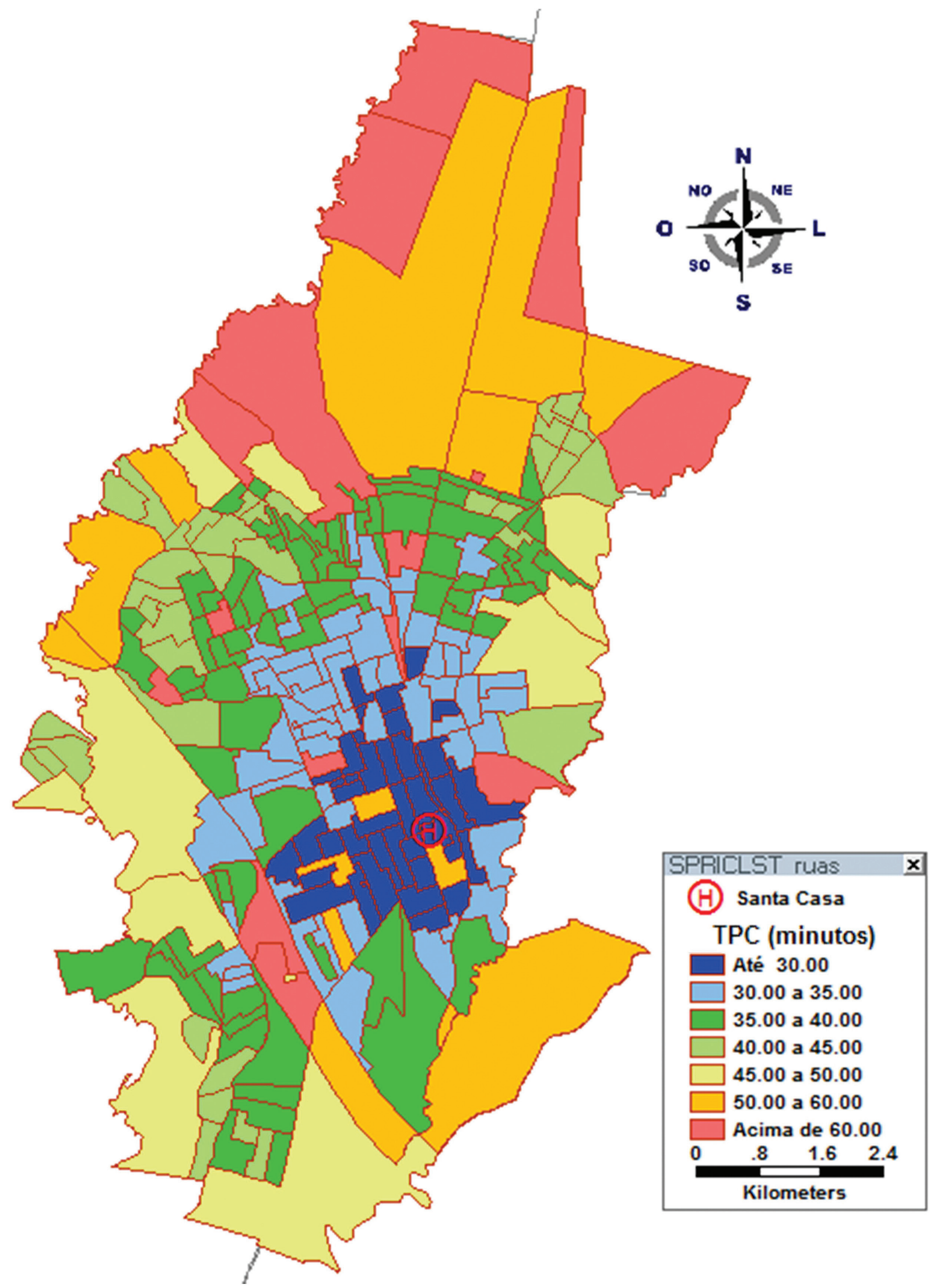

Figura 5 - Acessibilidade ao transporte coletivo de Rio Claro Fonte: Garcia (2012). 


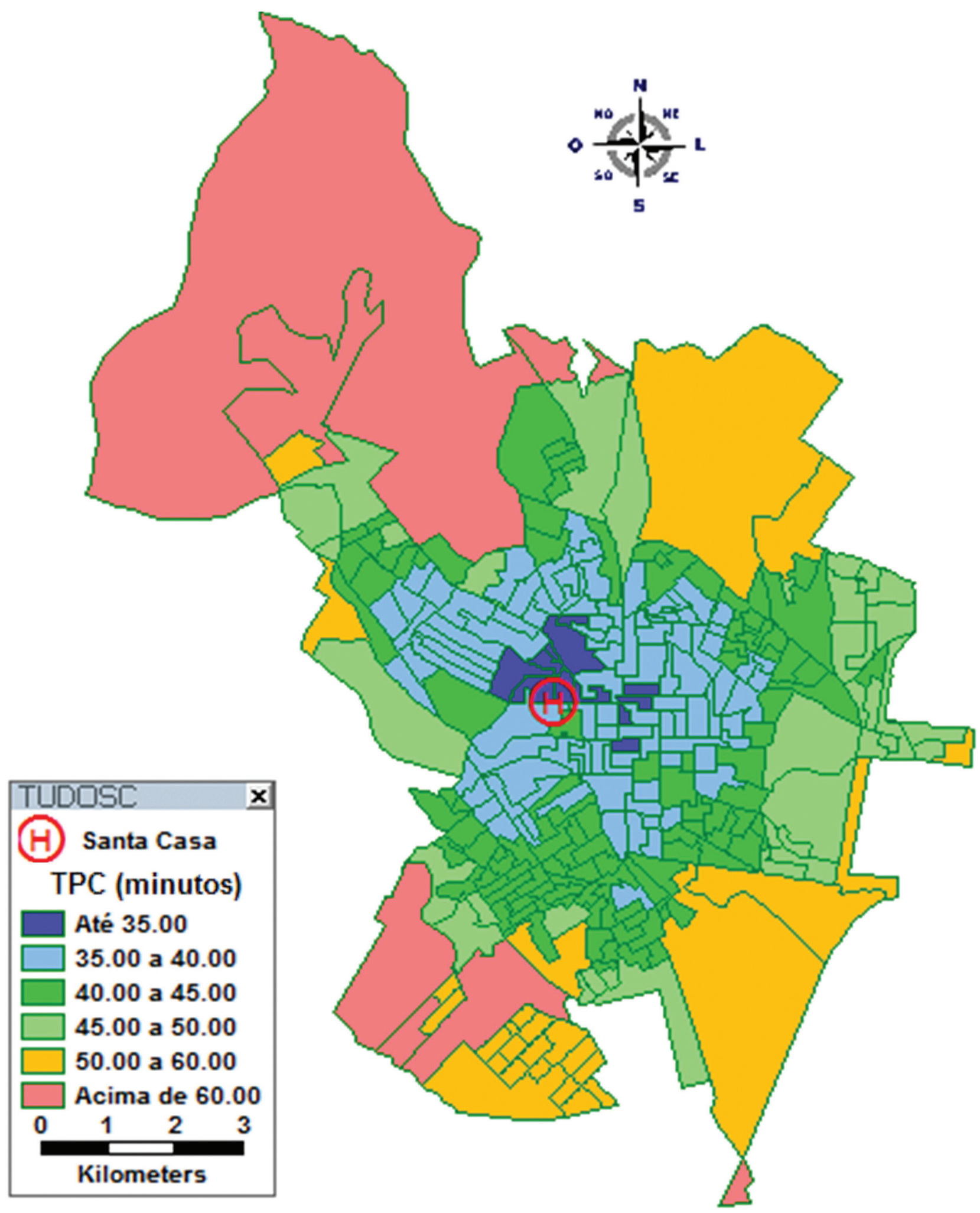

Figura 6 - Acessibilidade ao transporte coletivo de São Carlos Fonte: Garcia (2012). 
obtidos são consideravelmente altos (devido, principalmente, ao alto tempo de espera nos pontos). Dependendo da necessidade de cada usuário, o uso do transporte coletivo pode se tornar inviável. Quando se consideram os motivos de viagens, tais como consultas, exames, ou atendimentos pré-agendados, esse modo de transporte pode ser considerado aceitável.

Selecionaram-se sete setores censitários com maior número de usuários, em percentuais, como exemplo, que estão em destaque nas Figuras 7 e 8, para Rio Claro e São Carlos, respectivamente. Os percentuais de usuários em cada um desses setores em destaque são inferiores a 5\%. Ainda que se considerem os sete setores com maior percentual de usuários, pode-se concluir que não há uma concentração acentuada de pessoas em apenas uma determinada região.

\section{Análise com base no Rendimento Médio do Responsável}

Para a obtenção de um resultado mais preciso na análise de usuários em relação à renda, esperava-se utilizar os dados do Censo 2010 nesta pesquisa; no entanto, até a data da finalização da pesquisa, eles ainda não se encontravam disponíveis. A solução encontrada foi a utilização de dados do Censo 2000 (IBGE, 2012), partindo-se do pressuposto que os rendimentos tenham sido corrigidos, até 2010 , de modo a se manterem as mesmas proporções de 2000.

O salário mínimo que vigorava em janeiro de 2000 era de $\mathrm{R} \$ 136,00$ e, na época da realização do Censo 2010, o salário mínimo em vigor, em janeiro de 2010, era $\mathrm{R} \$ 510,00$ (DIEESE, 2012). Mesmo assim, os dados de 2000 poderiam, hipoteticamente, servir de referência para se obter uma proporção semelhante para o Rendimento Médio do Responsável (RMR) por

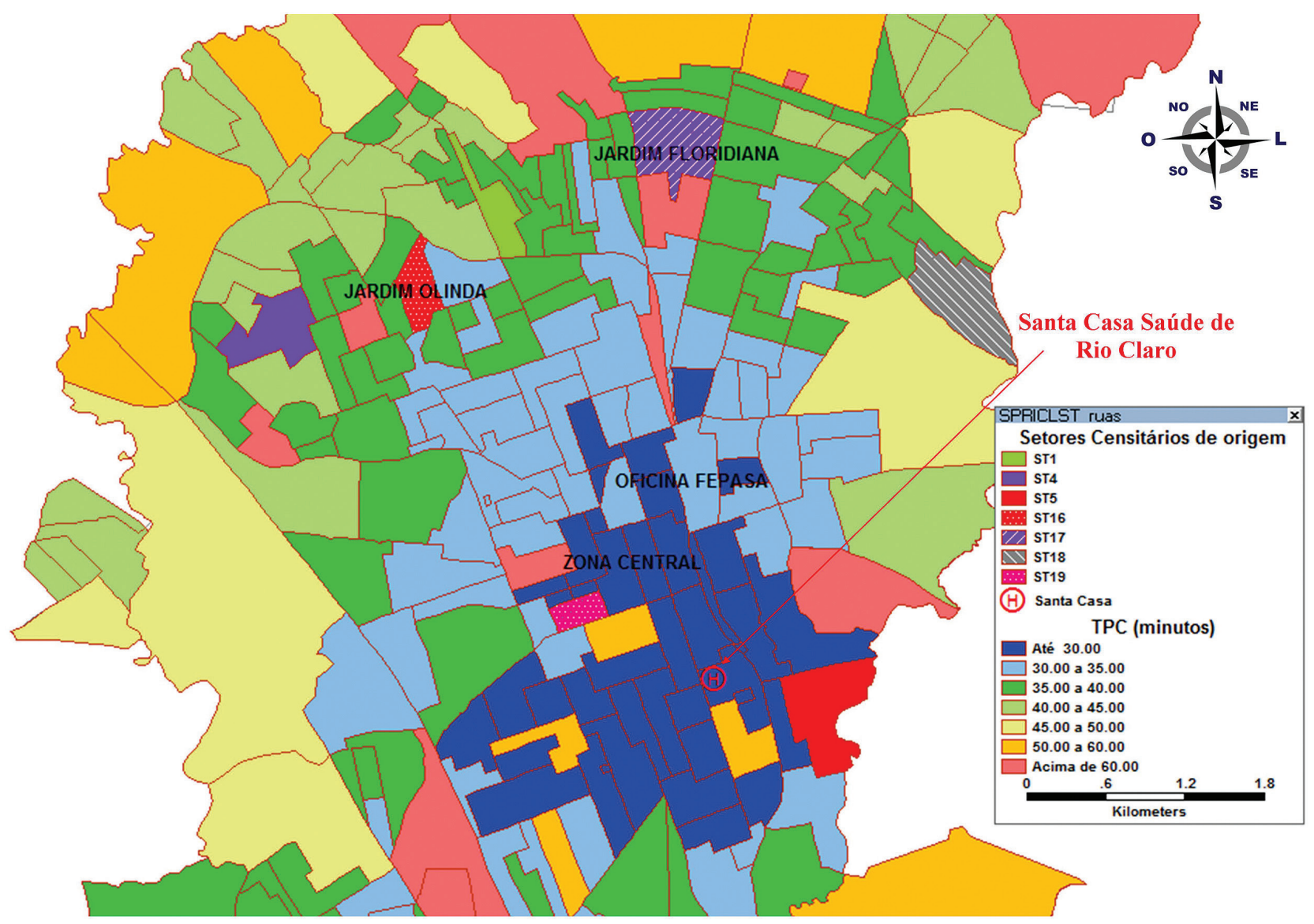

Figura 7 - Setores censitários de origem da maioria das viagens por TPC (Rio Claro) Fonte: Garcia (2012). 


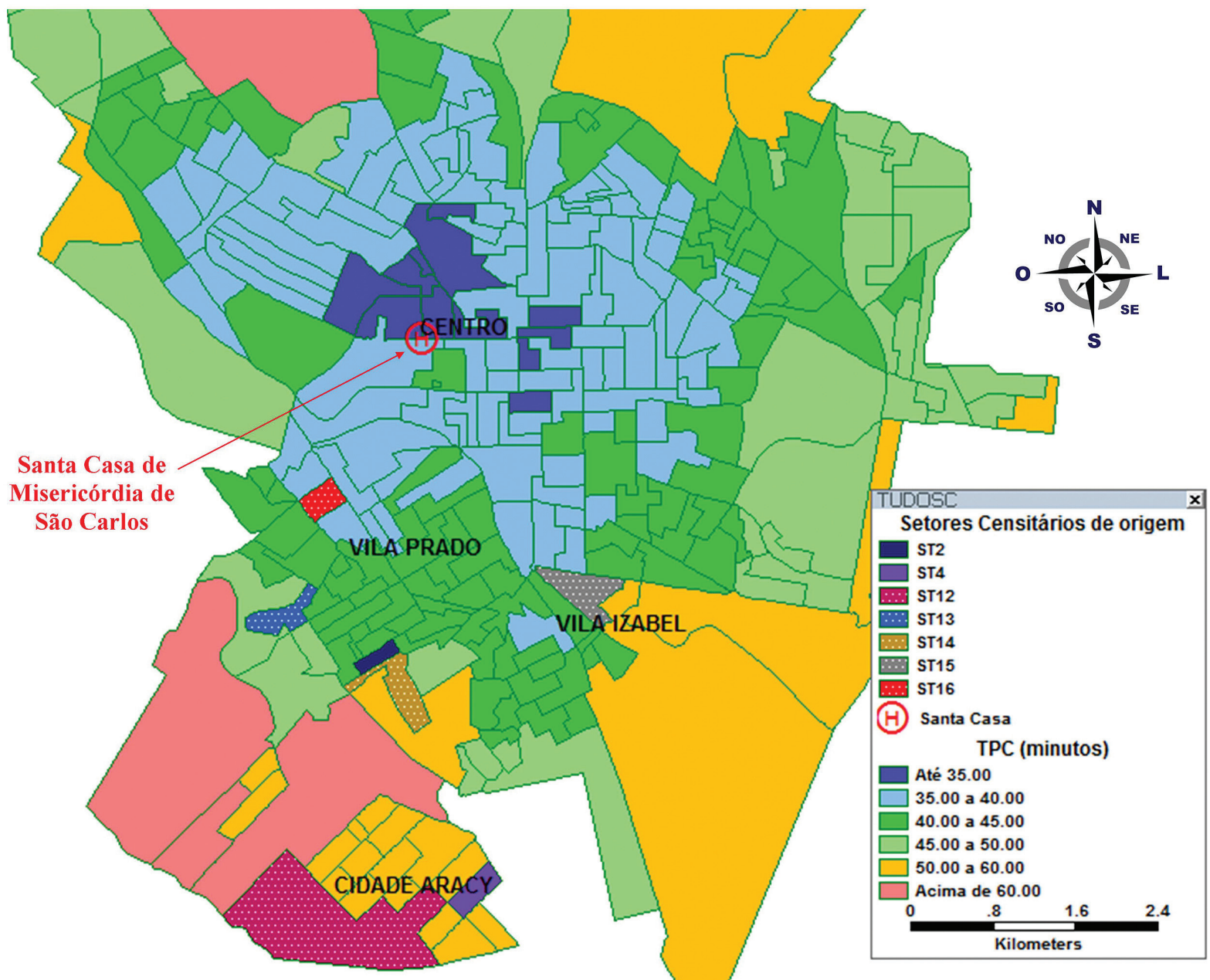

Figura 8 - Setores censitários de origem da maioria das viagens por TPC (Sc̃o Carlos) Fonte: Garcia (2012).

domicílio, por faixa salarial, nos setores censitários, com as devidas correções.

Outra dificuldade encontrada foi que o Censo 2010 possuía uma maior quantidade de setores censitários que o Censo 2000, indicando o surgimento de novos bairros residenciais ou mesmo o desmembramento de setores. 0 município de Rio Claro, em 2000, apresentava um total de 204 setores censitários (197 na área urbana) e, em 2010, esse número subiu para 278, com 263 deles localizados na área urbana. Isso representa um aumento de $36,3 \%$ no total de setores censitários em relação aos dados de 2000. O município de São Carlos tinha, em 2000, um total de 273 setores censitários e, em 2010, aumentou para 323 (292 na área urbana), com um aumento de 18,3\% no total de setores no período. Essa diferença é devido à criação de novos loteamentos e de desmembramento de setores censitário pelo IBGE.
Os dados do Censo 2000 informavam apenas o número de domicílios dentro de faixas de salários mínimos. Esses dados foram, então, tratados de maneira que se obtivesse o rendimento médio dos setores censitários, na unidade de salários mínimos recebidos pelo responsável do domicílio. Bielenki et al. (2008) desenvolveram uma pesquisa sobre o uso de geoprocessamento no planejamento de pesquisa origem-destino na cidade de São Carlos, onde utilizaram o rendimento médio dos setores censitários, com base no Censo 2000. Para a determinação do rendimento médio, os autores utilizaram uma equação semelhante à Equação 3.

$R M R=\frac{\sum(N D C x M I C)}{T D S}$

Onde RMR é o Rendimento Médio do Responsável; NDC é o Número de Domicílios da Classe; MIC é 
a Média do Intervalo da Classe; e TDS é o Total de Domicílios do Setor. Para efeito de cálculo do Rendimento Médio do Responsável, nesta pesquisa, optou-se por utilizar a mesma equação adotada por Bielenki et al. (2008).

Através dos dados obtidos, foram elaborados mapas temáticos para ilustrar o RMR de cada setor censitário. As Figuras 9 e 10 mostram, respectivamente, o RMR (em Salários Mínimos) de Rio Claro e de São Carlos. Comparando-se essas figuras, encontram-se algumas semelhanças entre as duas cidades: nas regiões centrais concentramse as populações com RMR mais altos, contrastando com as de menor RMR que estão mais presentes nas áreas periféricas. Isso indica que o acesso à maioria dos serviços disponíveis nas cidades privilegia as populações que residem mais próximas às áreas centrais, onde geralmente se localiza a maioria dos serviços públicos em cidades de porte médio (saúde, lazer, transportes etc.).

Em Rio Claro (Figura 9), através do cálculo do RMR, obtido para cada setor censitário, têm-se os seguintes resultados: 1\% dos setores censitários estão na faixa de até 2 Salários Mínimos (SM); 4,1\%, na faixa de 2 a 3 SM; 35\%, na faixa de 3 a 5 SM; 39,1\%, na faixa de 5 a 8 SM; e $20,8 \%$ na faixa acima de 8 SM.

Em São Carlos (Figura 10), os resultados obtidos foram: 1,6\% dos setores censitários estão na faixa de até 2 SM; $5,7 \%$ estão na faixa de 2 a 3 SM; $29,8 \%$, na faixa de 3 a 5 SM; 40,8\%, na faixa de 5 a 8 SM; e $22,1 \%$ na faixa acima de 8 SM. Além disso, em um raio de $3 \mathrm{~km}$ da Santa Casa de Misericórdia de São Carlos, tem-se que a maioria dos setores censitários está localizada nas faixas de RMR de 5 a 8 SM e acima de 8 SM.

\section{Cruzamento dos dados censitários com os dados das viagens dos usuários}

Através do cruzamento de dados da RMR do Censo 2000, de cada setor censitário, com as origens das viagens, pode-se traçar um panorama aproximado do perfil dos usuários que compareceram aos hospitais abordados, no dia da pesquisa de campo. Para efeito de estudo, considerou-se como rendimento médio do usuário do hospital aquele associado ao setor censitário de origem (o IBGE dispõe apenas do dado agregado do setor), não sendo, necessariamente, o rendimento médio efetivo do usuário entrevistado.

As viagens segundo o modo de transporte e RMR

A partir dos dados dos meios de transportes utilizados pelos usuários para se dirigirem às santas casas e, comparando com os dados de RMR da família que teve um membro identificado na pesquisa, podese ter uma visão aproximada de quais são os níveis salariais das famílias que fazem uso desse serviço de saúde. As Figuras 11 e 12 mostram a distribuição percentual das viagens em função das classes de renda para Rio Claro e São Carlos, respectivamente.

Em Rio Claro, o automóvel foi o meio de transporte mais utilizado por usuários originários de zonas censitárias com classes de rendimento acima de 3 a $5 \mathrm{SM}(34,09 \%)$. As viagens a pé foram mais realizadas por pessoas de zonas de classe de RMR acima de 8SM (58,33\%). 0 transporte público coletivo (ônibus) foi o modo mais utilizado pela classe de 3 a 5 SM. Curiosamente, a bicicleta serviu como meio de transporte para $25 \%$ dos indivíduos residentes em zonas censitárias com RMR entre 3 e 5 SM e 5 e 8 SM.

Em São Carlos, os modos automóvel, a pé e ônibus foram os meios de transporte mais utilizados por pessoas originárias de zonas com RMR acima de $8 \mathrm{SM}$. As viagens por ônibus foram mais realizadas por moradores de zonas com RMR de 2 a 3 SM. Em relação às motocicletas, elas foram mais usadas por usuários de classes de RMR acima de 5 a 8 SM. Ao contrário do que ocorreu em Rio Claro, o modo bicicleta não obteve valores significativos em São Carlos.

Além disso, 3,39\% dos usuários do automóvel e $50 \%$ dos usuários que utilizaram "outros modos" de transporte para as viagens ao hospital eram originários de setores censitários que não existiam no Censo 2000, geralmente periféricos.

Análise baseada na quantidade de usuários por setor censitário de origem

Os dados de campo apontaram que a maior quantidade de usuários dos serviços prestados pelas santas casas está na faixa de RMR de 3 a 5 SM, 


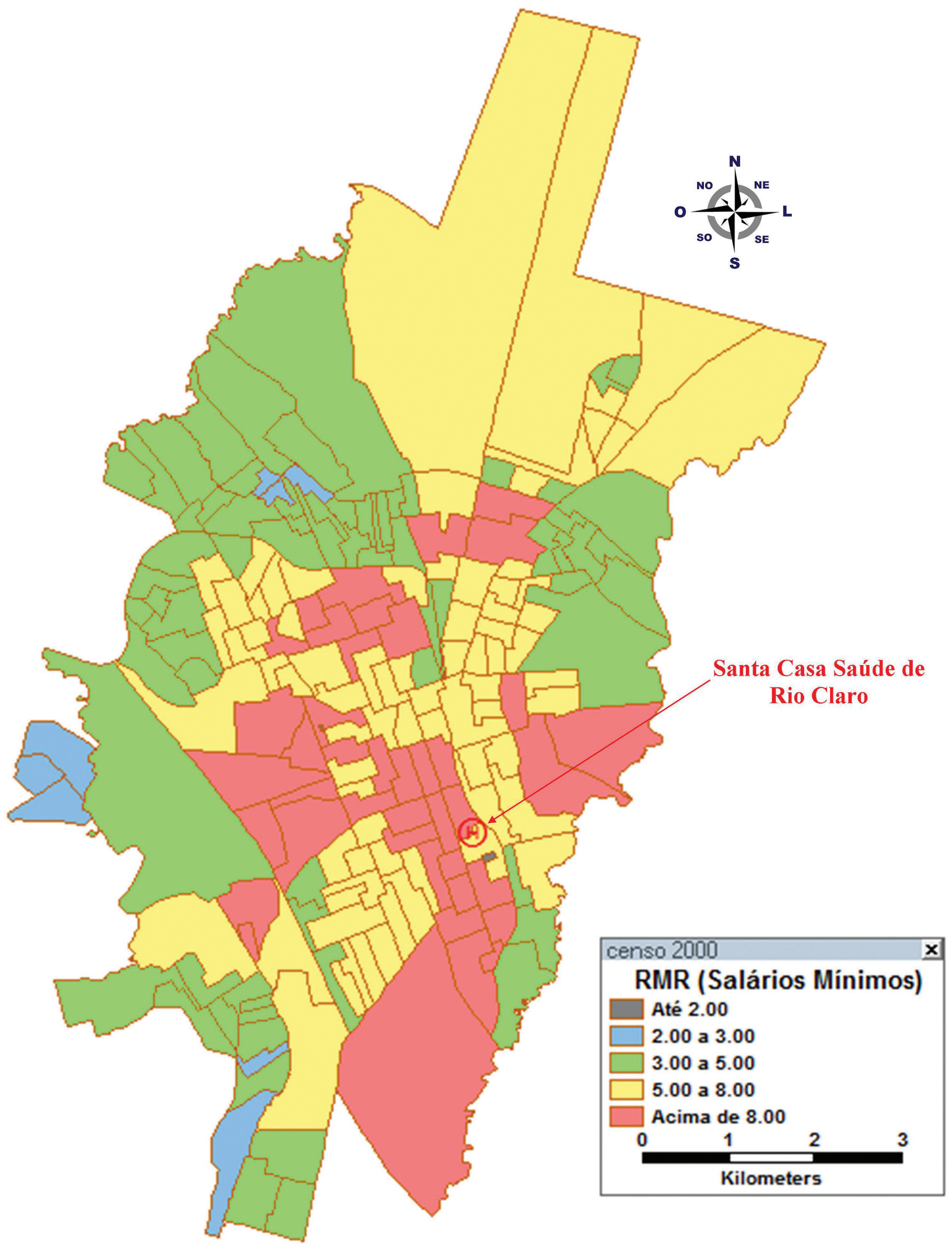

Figura 9 - RMR por setor censitário em Rio Claro (Censo 2000) Fonte: Garcia (2012). 


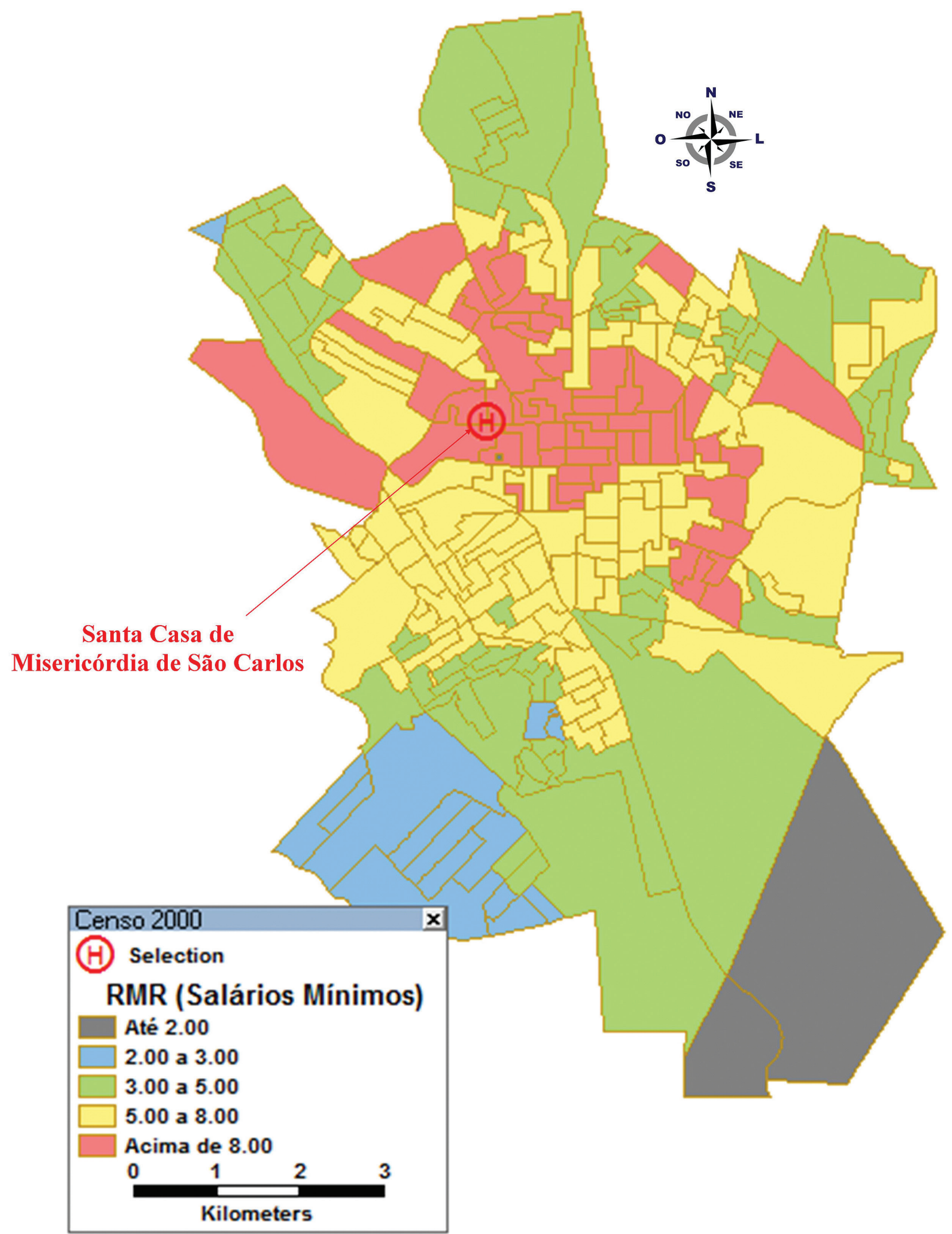

Figura 10 - RMR por setor censitário em São Carlos (Censo 2000) Fonte: Garcia (2012). 


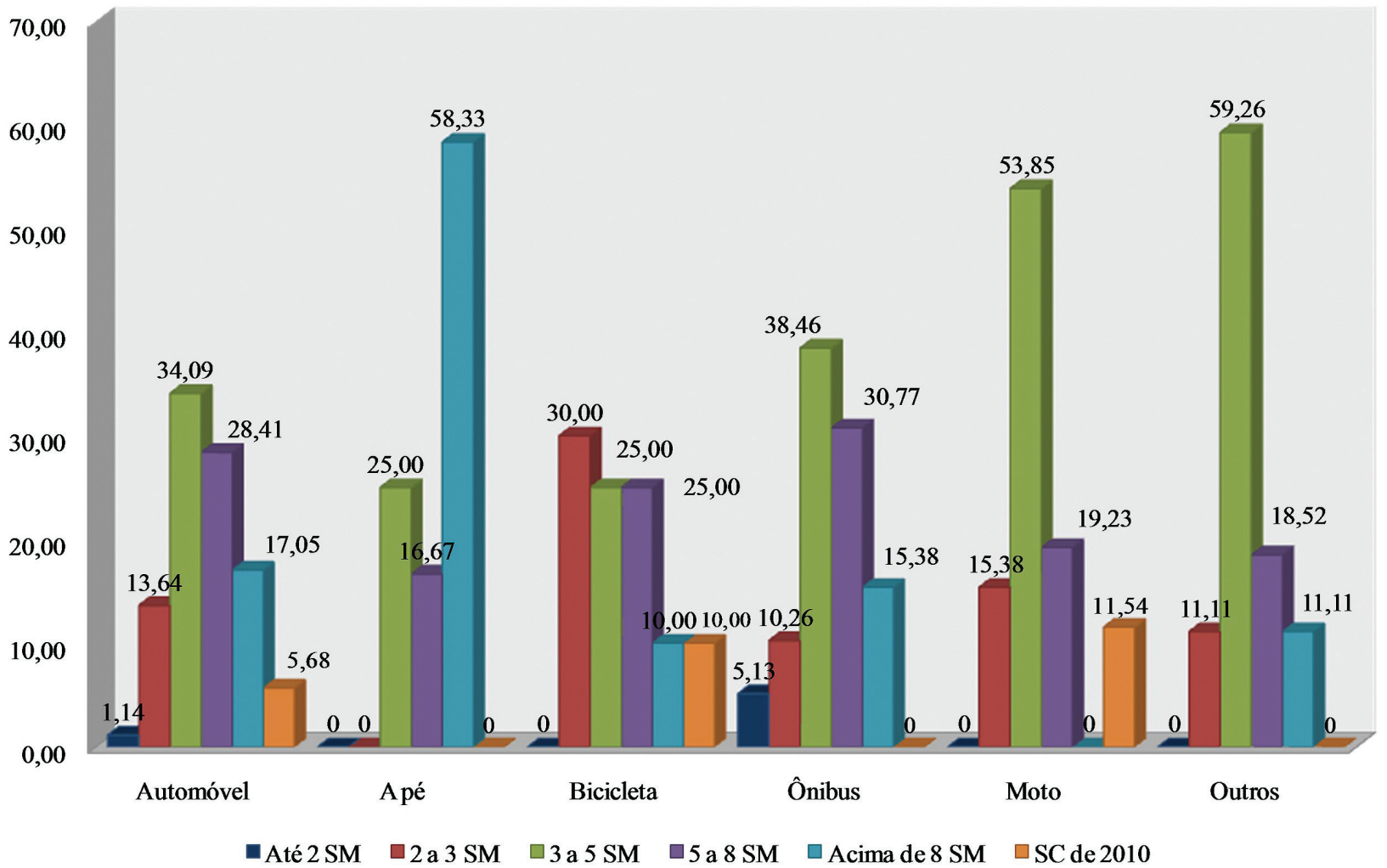

Figura 11 - Modo de transporte em função das classes de rendimento em Rio Claro Fonte: Garcia (2012).

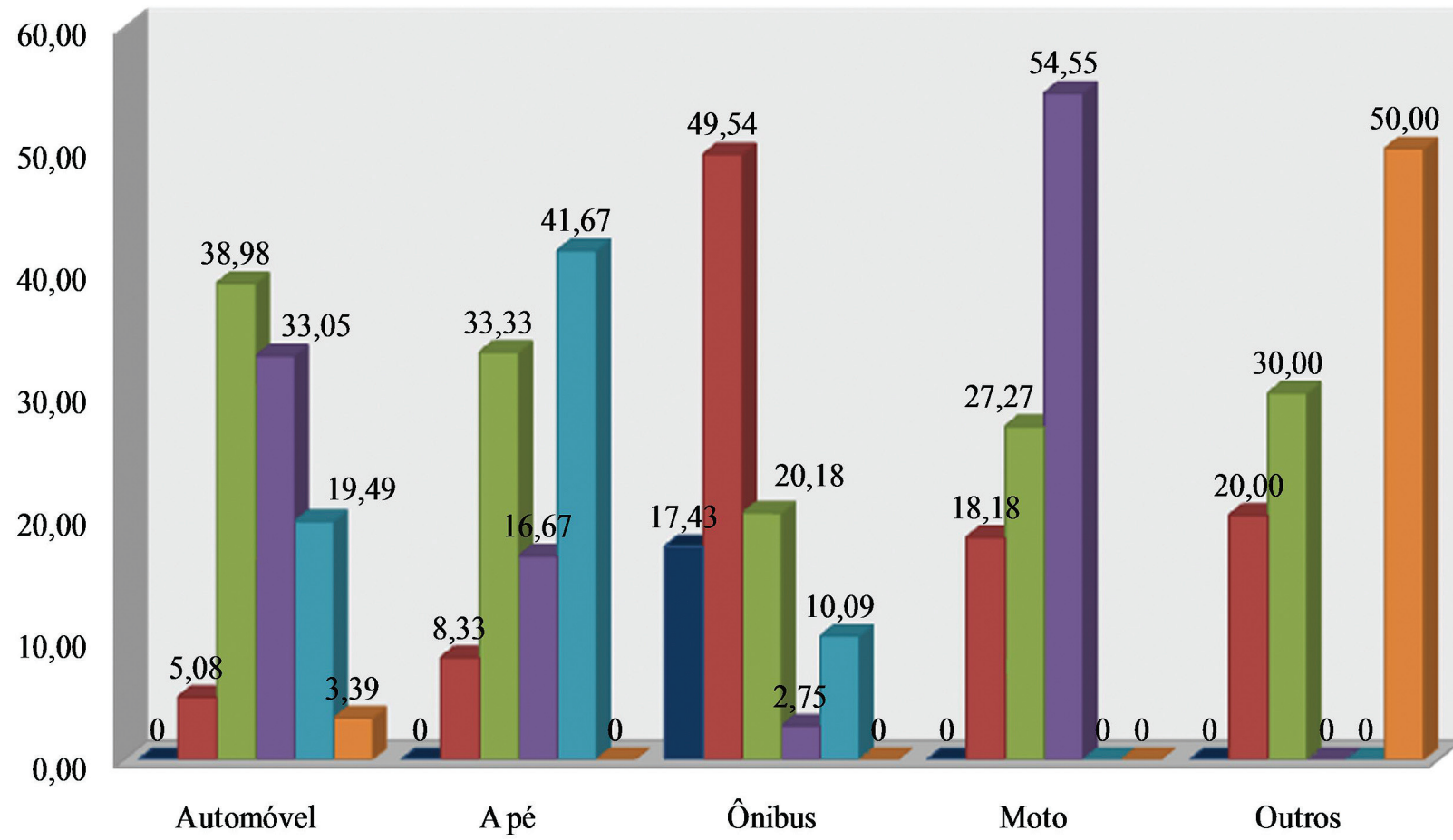

-Até $2 \mathrm{SM} \quad \square 2$ a $3 \mathrm{SM} \quad \square 3 \mathrm{a} 5 \mathrm{SM} \quad \square 5 \mathrm{a} 8 \mathrm{SM} \quad \square$ Acima de $8 \mathrm{SM} \quad \square \mathrm{SC}$ de 2010

Figura 12 - Modo de transporte em função das classes de rendimento em São Carlos Fonte: Garcia (2012). 
com 34,29\% (Rio Claro) e 40,85\% (São Carlos). Em seguida, a faixa entre 5 e $8 \mathrm{SM}$, na mesma ordem, com $25,24 \%$ e $28,64 \%$. Esses dados estão detalhados nas Figuras 13 e 14. Essas figuras mostram que a repartição das viagens, segundo as classes de RMR, guarda uma razoável similaridade para as duas cidades estudadas.

Através da análise desses resultados obtidos em Rio Claro observa-se a predominância da população originária de setores censitários classificados na faixa de 3 a 5 SM, em quatro dos seis modos de transporte considerados na pesquisa para a realização das viagens ao hospital. Em São Carlos, a faixa de 3 a
$5 \mathrm{SM}$ foi mais representativa nas viagens realizadas por automóvel e "outros". A parcela da população que mais utilizou o transporte público coletivo em São Carlos era originária de setores classificados na faixa de 2 a 3 SM.

É interessante observar que a população originária de setores de faixa salarial acima de 8 SM realizou a maioria das viagens a pé, em ambos os estudos de caso. Isso talvez se deva por dois motivos: proximidade da residência do usuário com a localização do hospital (permitindo viagens a pé); o fato dos hospitais estarem inseridos em áreas censitárias classificadas na faixa acima de 8 SM.

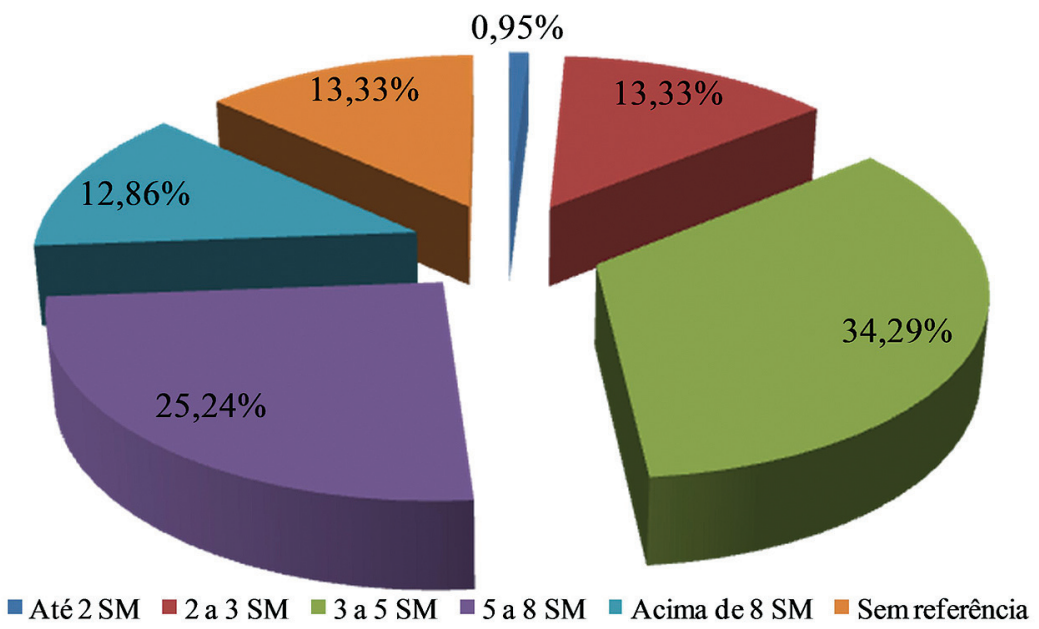

Figura 13 - Percentagem de usuários em função das classes de rendimento em Rio Claro

Fonte: Garcia (2012).

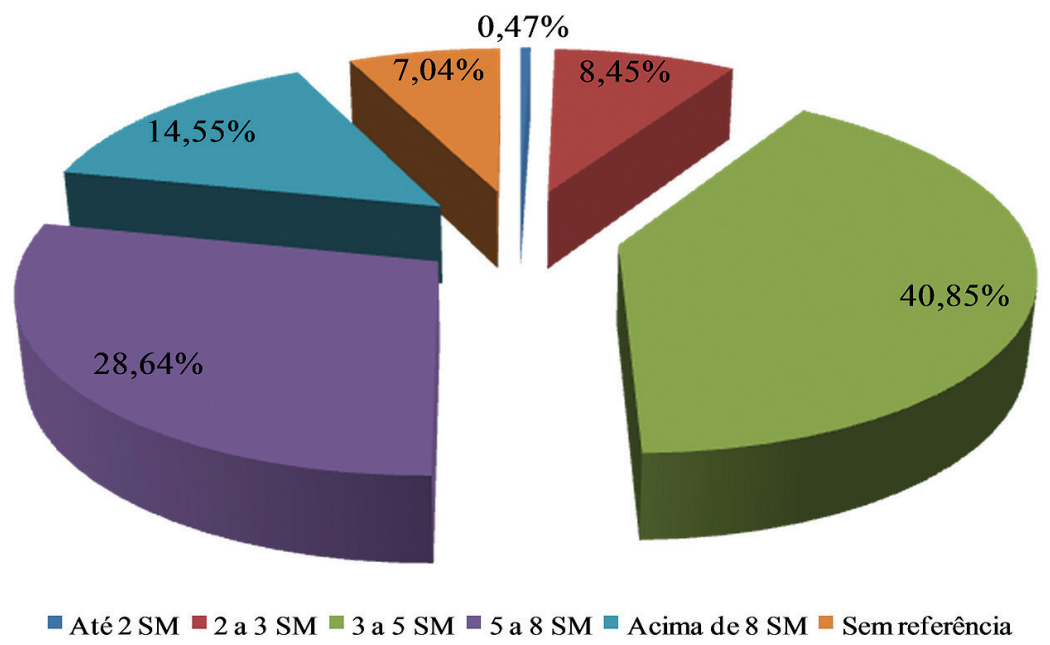

Figura 14 - Percentagem de usuários em função das classes de rendimento em São Carlos Fonte: Garcia (2012). 


\section{Relação entre a acessibilidade (tempo) e o RMR dos setores censitários}

Para se classificar as zonas censitárias de acordo com a acessibilidade, cruzaram-se os dados das tabelas tempo de viagem com os dados do RMR de cada setor censitário, ambas obtidas através do software de SIG.

Além disso, compararam-se os valores do tempo de viagem de cada modo de transporte, por faixa de RMR, de cada setor censitário. Para isso, calculouse a média aritmética do tempo de viagem de cada modo de transporte em todas as faixas de RMR. Em Rio Claro, as faixas de maior RMR são aquelas que obtiveram menor tempo médio de viagem, nos três modos de transporte considerados (automóvel, a pé e ônibus), com exceção da faixa até 2 SM, pois há um setor censitário nessa faixa de RMR localizado próximo à Santa Casa Saúde. Em São Carlos, as faixas de maior RMR também são as que obtiveram, em geral, menor tempo médio de viagem em relação ao hospital, nos três modos de transporte considerados nesta pesquisa.

Como muitos dos setores censitários de 2010 permaneceram inalterados quanto à área e o identificador, utilizou-se o mapa do Censo 2010 apenas para ilustrar, de forma mais atualizada, as regiões classificadas de acordo com a acessibilidade. Alguns dados, como a faixa de RMR, podem não condizer exatamente com a realidade de 2010 , devido a estes ajustes, já que as análises foram feitas com base no mapa do Censo 2000. Mas é um parâmetro que serve para avaliar as regiões que poderiam ser mais bem atendidas pelo transporte público coletivo e que ainda não o são. Para facilitar a visualização e destacar alguns dos setores censitários com maior acessibilidade por faixa de RMR, foram construídos os mapas das Figuras 15 e 16, para as cidades de

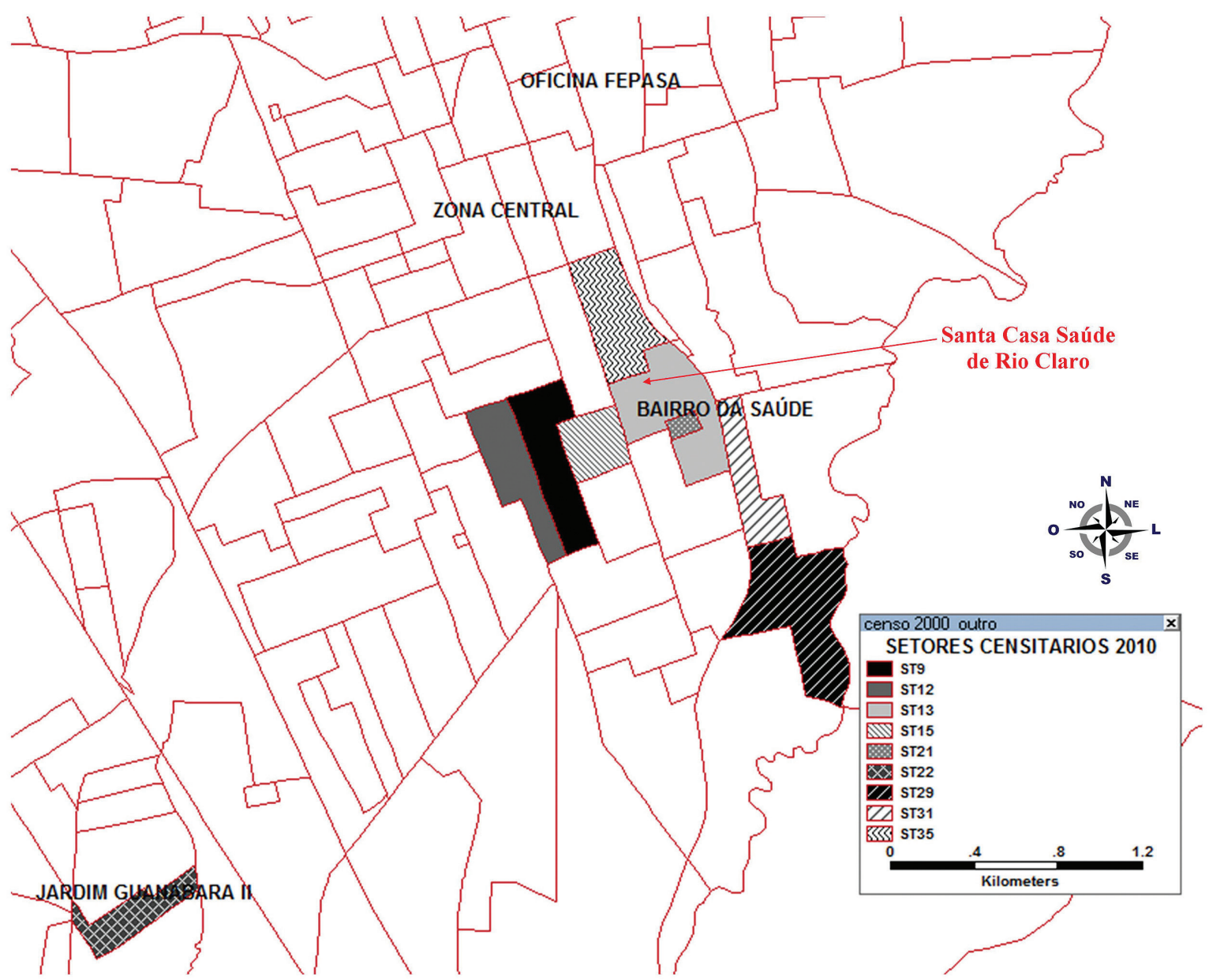

Figura 15 - Setores censitários com maior acessibilidade em Rio Claro Fonte: Garcia (2012). 
Rio Claro e São Carlos, respectivamente. Para que as figuras não ficassem muito sobrecarregadas, a respectiva faixa de RMR de cada setor em destaque está contida na Tabela 2.

Analisando-se as Figuras 15 e 16 e a Tabela 2, observa-se que, mesmo localizados em regiões distantes aos hospitais, alguns setores censitários apresentaram alta acessibilidade por meios motorizados, principalmente o ônibus, o que pode significar uma quantidade maior de linhas de transporte coletivo nessas regiões.

Para identificar alguns dos setores censitários com menor acessibilidade por faixa de RMR, têm-se as Figuras 17 (Rio Claro) e 18 (São Carlos).

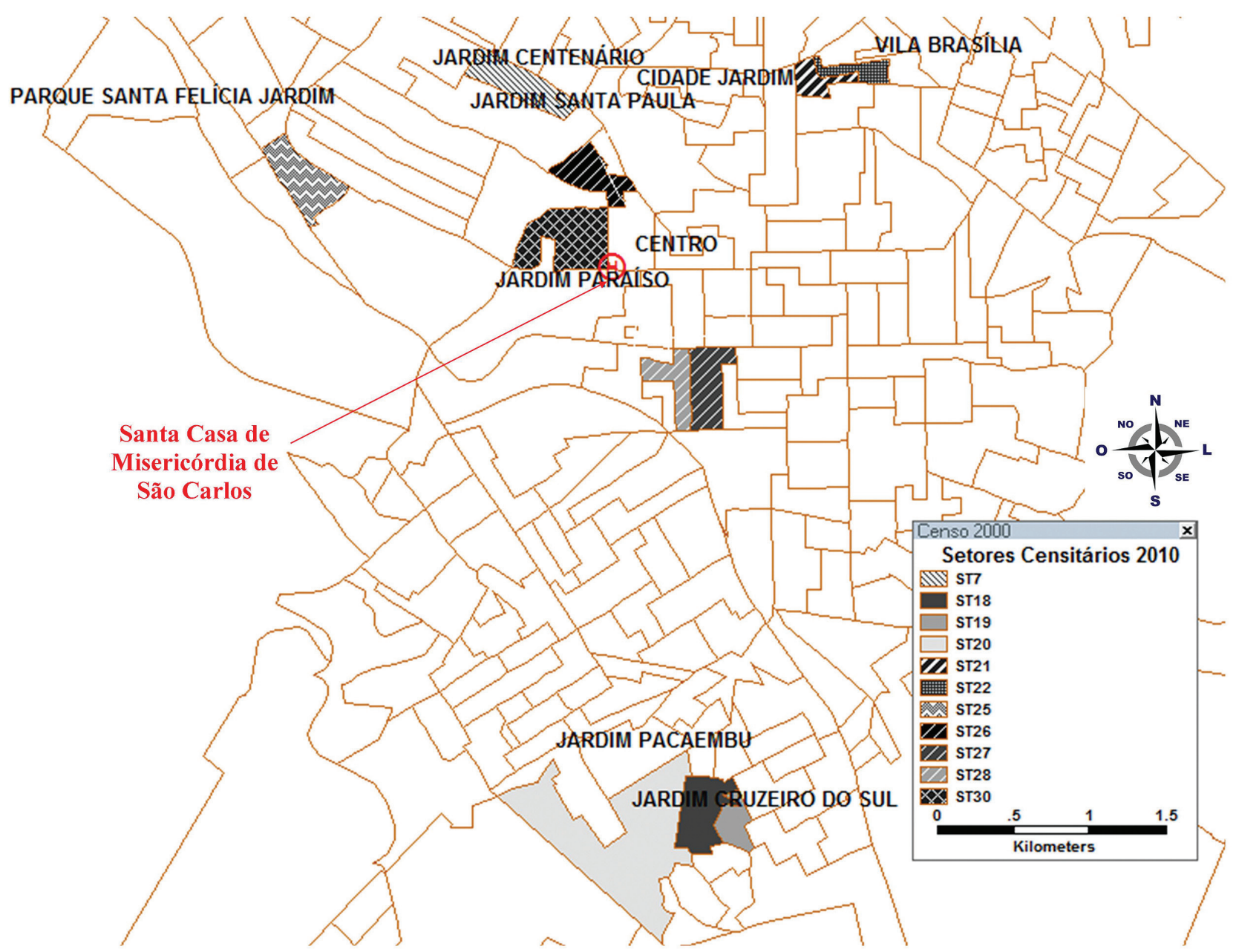

Figura 16 - Setores censitários mais acessíveis de São Carlos Fonte: Garcia (2012).

Tabela 2 - Setores censitários considerados mais acessíveis por faixa de RMR

\begin{tabular}{ccccccc}
\hline \multirow{2}{*}{ RMR } & \multicolumn{3}{c}{ Rio Claro } & \multicolumn{3}{c}{ São Carlos } \\
\cline { 2 - 6 } & Automóvel & Ônibus & A pé & Automóvel & Ônibus & A pé \\
\hline Até 2 SM & ST21 & ST21 & ST21 & - & - & - \\
2 a 3 SM & ST22 & ST22 & ST22 & ST18, ST19 e ST20 & ST18, ST19 e ST20 & ST18, ST19 e ST20 \\
3 a 5 SM & ST29 e ST31 & ST29 e ST31 & ST29 e ST31 & ST21 e ST22 & ST21, ST22 e ST25 & ST21 e ST25 \\
5 a 8 SM & ST12 e ST13 & ST12 e ST13 & ST12 e ST13 & ST26, ST27 e ST28 & ST7 e ST26 & ST26, ST27 e ST28 \\
Acima de 8 SM & ST15 e ST35 & ST15 e ST35 & ST15 e ST35 & ST14 e ST30 & ST14 e ST30 & ST14 e ST30 \\
\hline
\end{tabular}

Fonte: Garcia (2012). 
Comparando-se as Figuras 17 e 18 com a Tabela 3, observa-se que alguns setores censitários localizados em regiões mais próximas ao hospital apresentaram baixa acessibilidade por transporte coletivo, como o ST50, em Rio Claro, e o ST47, em São Carlos, por exemplo.

Dados mais aprofundados desta pesquisa podem ser encontrados em Garcia (2012).

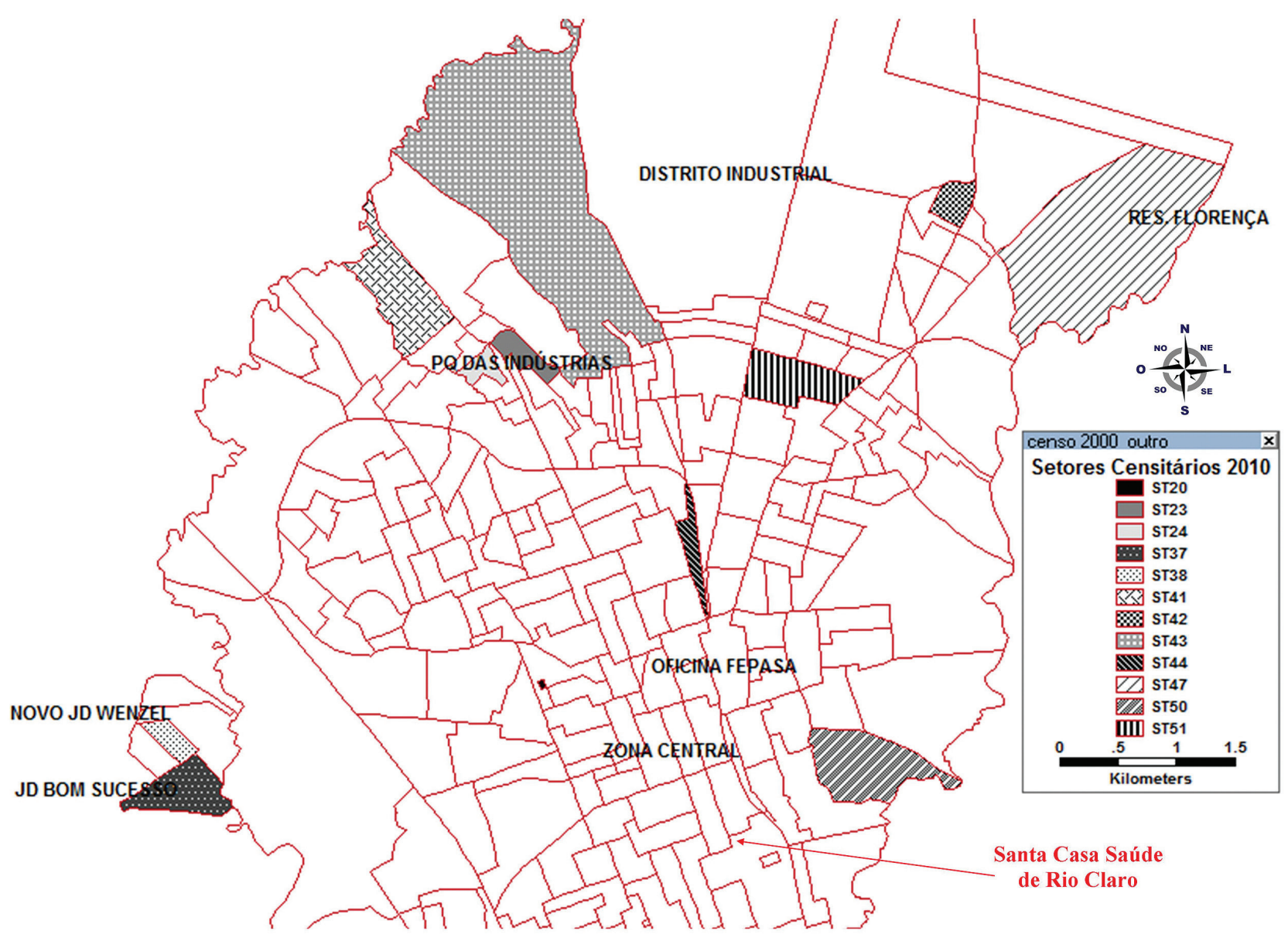

Figura 17 - Setores censitários menos acessiveis em Rio Claro Fonte: Garcia (2012).

Tabela 3 - Setores censitários considerados menos acessiveis por faixa de RMR

\begin{tabular}{ccccccc}
\hline \multirow{2}{*}{ RMR } & \multicolumn{3}{c}{ Rio Claro } & \multicolumn{3}{c}{ São Carlos } \\
\cline { 2 - 6 } & Automóvel & Ônibus & A pé & Automóvel & Onibus & A pé \\
\hline Até 2 SM & - & ST20 & ST20 & - & - & - \\
2 a 3 SM & ST37 e ST38 & ST37 e ST38 & ST23 e ST24 & ST32 e ST33 & ST32 e ST33 & ST32 e ST33 \\
3 a 5 SM & ST43 e ST44 & ST41 & ST42 & ST4 e ST37 & ST4 e ST37 & ST4 e ST37 \\
5 a 8 SM & ST47 & ST47 & ST47 & ST39 e ST40 & ST39 e ST40 & ST39 e ST40 \\
Acima de 8 SM & ST50 e ST51 & ST50 e ST51 & ST51 & ST43 e ST45 & ST46 e ST47 & ST43, ST45 e ST46 \\
\hline
\end{tabular}

Fonte: Garcia (2012). 


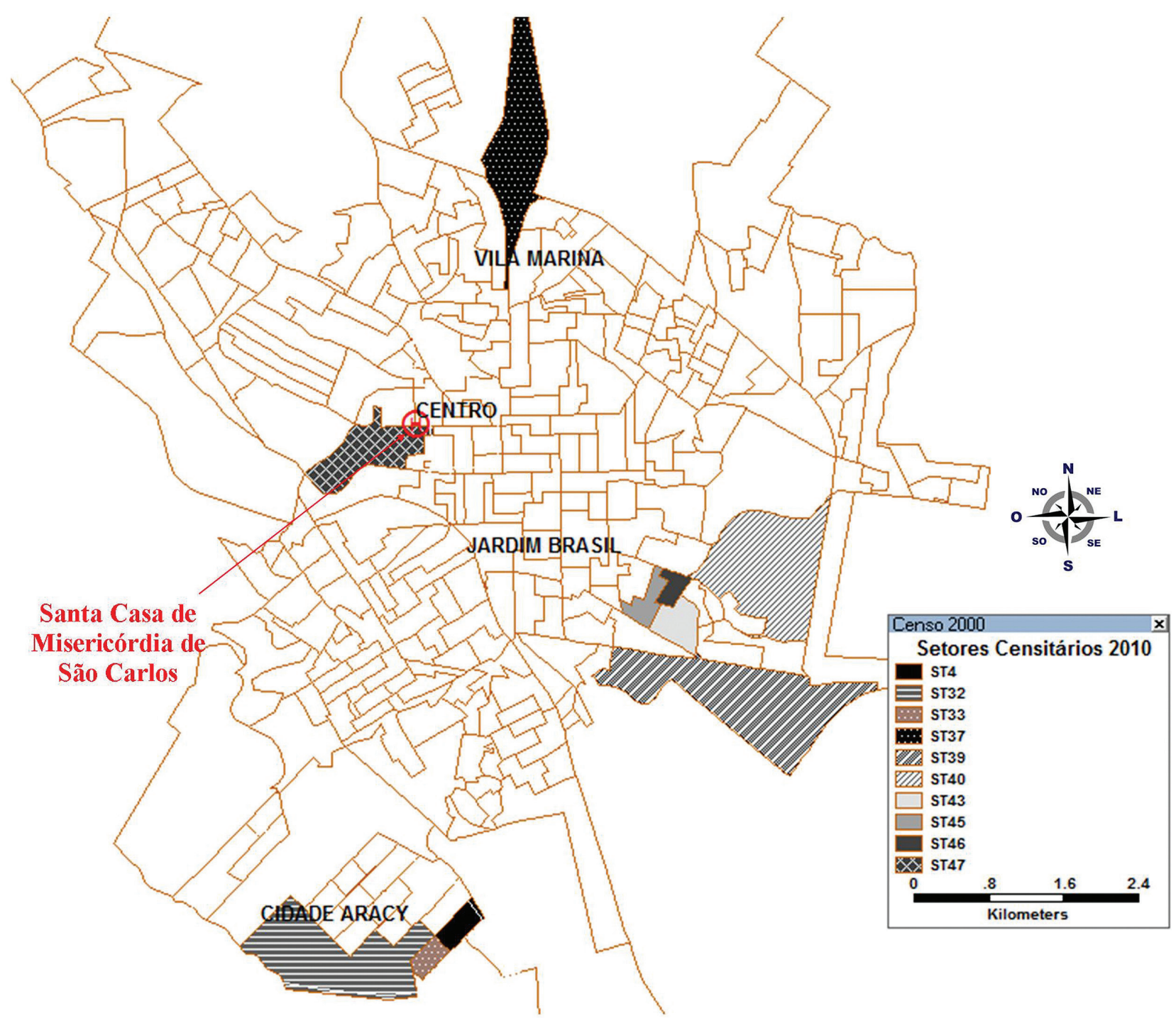

Figura 18 - Setores censitários com menor acessibilidade em São Carlos Fonte: Garcia (2012).

\section{Conclusão}

Em ambos os estudos de caso, observou-se que a parcela da população (menor renda) que supostamente deveria mais utilizar os serviços públicos de saúde, em parte, não foi aquela encontrada pela pesquisa. É importante ressaltar que os usuários entrevistados foram apenas aqueles que adentravam ao hospital. Essas pessoas eram abordadas do lado de fora do empreendimento, nos acessos. Com isso, não se têm disponíveis as informações de usuários que estavam internados. Caso fosse disponibilizado o banco de dados do hospital (que é sigiloso), ter-se-ia um diagnóstico mais preciso do perfil dos usuários (atendidos pelo SUS) quanto ao rendimento médio e a necessidade de transporte público da região de origem. Assim, se poderia confirmar ou não com mais fundamento a hipótese com base em dados reais do paciente que está internado, dos visitantes, daqueles que vão ao hospital para a realização de exames, de tratamentos específicos (hemodiálise, radioterapia etc.), dentre outros motivos relacionados aos serviços de saúde oferecidos pelos empreendimentos.

A Santa Casa Saúde de Rio Claro, além do convênio com o SUS, atende outros planos de saúde particulares, e possui um plano de saúde próprio. A Santa Casa de Misericórdia de São Carlos também possui convênio com o SUS e com outros 15 planos de saúde particulares, segundo a direção do hospital. Isso mostra uma grande quantidade de usuários de 
planos de saúde privados atendidos pelos hospitais sem a necessidade de um atendimento público e gratuito pelo SUS.

0 resultado encontrado nesta pesquisa não significa que a população com menor rendimento médio não tenha acesso aos serviços de saúde, mas deixa claro que a população com maior rendimento pode ser a que mais frequenta o hospital, talvez pela facilidade que um plano de saúde oferece em termos de consultas, exames etc., além do fator informação, pois quem tem informação tende a buscar mais os serviços de saúde com o objetivo da prevenção (Barata, 2008).

Comparando-se os três modos de transporte considerados, a preferência pelo uso do automóvel ficou evidente. As viagens a pé, em sua maioria, foram realizadas por pessoas residentes em áreas próximas aos hospitais.

Os resultados desta pesquisa são interessantes e apresentam dados importantes à gestão pública a respeito da acessibilidade dos setores censitários aos hospitais abordados. Nas duas cidades, os hospitais estão localizados em regiões centrais ou próximas delas. Em Rio Claro, o desenho das linhas fez com que 10 delas passassem ao lado do PGV. Em São Carlos, por outro lado, ficou clara uma preocupação de que o sistema público de transporte coletivo tivesse a maioria das suas linhas (19) trafegando nas proximidades da Santa Casa. Apesar da densidade de linhas de transporte coletivo público por ônibus no entorno das santas casas, ficou evidenciado que a frequência dessas mesmas linhas, considerando as duas cidades, é muito pequena, fazendo com que os usuários fiquem quase uma hora esperando pelo ônibus, se o anterior tivesse acabado de passar pelo ponto. Caso as pessoas tenham conhecimento suficiente sobre o sistema, elas podem ficar esperando em casa e se dirigir ao ponto em horários próximos à passagem do coletivo. No entanto, nas cidades brasileiras, em geral, a confiabilidade de que os ônibus passem nos horários previstos é baixa.

É importante salientar que esses dados obtidos, principalmente em relação ao transporte coletivo, podem variar em função da disponibilidade do número de linhas e do tempo de espera entre um ônibus e outro. 0 tempo de viagem por automóvel, ao se fazer uma análise mais minuciosa, considerandose dados como tempo de parada em cruzamentos e semáforos, faria com que os dados fossem mais próximos à realidade. Os tempos de viagem estimados para o modo de viagem a pé, em tese, seriam aqueles mais precisos.

A análise realizada neste trabalho tratou como objeto um empreendimento hospitalar, porém a metodologia aplicada pode ser reproduzida para análises de qualquer tipo de equipamento público, independente da área de atuação. É importante salientar que as principais análises realizadas só foram possíveis devido ao uso de um software de SIG, que é uma ferramenta de fundamental importância em se tratando de Gestão Urbana e de Transportes.

É preciso tomar os dados e, por consequência, as análises desta pesquisa com cautela, que, devido à indisponibilidade de muitos dados importantes, foram estimados de forma indireta. No entanto, mais que os dados quantitativos, considera-se importante a metodologia apresentada e que pode ser empregada em outros municípios e considerando outros equipamentos públicos.

\section{Agradecimentos}

Os autores agradecem à Coordenação de Aperfeiçoamento de Pessoal de Nível Superior (Capes), ao Conselho Nacional de Desenvolvimento Científico e Tecnológico (CNPq) e à Rede IberoAmericana de Estudo em Polos Geradores de Viagens (Rede PGV) pelo suporte técnico e financeiro disponibilizados.

\section{Referências}

Associação Nacional de Transportes Públicos - ANTP. (2013). Critérios para avaliação e diagnóstico da gestão das organizações de transporte público e trânsito. São Paulo: ANTP.

Barata, R. B. (2008). Acesso e uso de serviços de saúde: considerações sobre os resultados da Pesquisa de Condições de Vida 2006. São Paulo em Perspectiva, 22(2), 19-29.

Bielenki, C., Jr., Raia, A. A., Jr., \& Silva, A. N. R. (2008). 0 uso de geoprocessamento no planejamento de pesquisa origem-destino no município de São Carlos. Revista Minerva, 5(2), 159-167.

Boni, V., \& Quaresma, S. J. (2005). Aprendendo a entrevistar: como fazer entrevistas em Ciências Sociais. Em Tese, 2(1/3), 68-80. 
Brasil (2012, 4 de janeiro). Lei no 12.587, de 3 de janeiro de 2012. Institui as diretrizes da Política Nacional de Mobilidade Urbana: revoga dispositivos dos Decretos-Leis nos 3.326, de 3 de junho de 1941, e 5.405, de 13 de abril de 1943, da Consolidação das Leis do Trabalho (CLT), aprovada pelo Decreto-Lei no 5.452, de 1 o de maio de 1943, e das Leis nos 5.917, de 10 de setembro de 1973, e 6.261, de 14 de novembro de 1975; e dá outras providências. Brasília: Diário Oficial da União.

Costa, M. C. (2008). Um índice de mobilidade urbana sustentável (Tese de doutorado). Departamento de Transportes, Escola de Engenharia de São Carlos, Universidade de São Paulo, São Carlos.

Departamento Intersindical de Estatísticas e Estudos Socioeconômicos - DIEESE (2012). Salário mínimo nominal e necessário. Recuperado em 03 de março 2012, de http:// www.dieese.org.br/rel/rac/salminMenu09-05.xml\#2009.

Ferreira, R. V., \& Raffo, J. G. (2013). Visualização cartográfica da acessibilidade geográfica aos postos de saúde da região rural de Registro (SP). Confins-Revista Franco-Brasileira de Geografia, 18.

Freire, G. J. M., Oliveira, R. H., Santana, S. A., Cintra, I. S., Wagner, I. C. O., \& Torres, A. A. D. (2008). Geoprocessamento e análise de acessibilidade no hospital municipal Odilon Behrens - Belo Horizonte. In Anais do II Simpósio Brasileiro de Ciências Geodésicas e Tecnologias da Geoinformação. Recife.

Gamma \& Haaze, T. (2007). Towards the development of a transport accessibility index. Dublin: Pobal.

Garcia, P. B. M. (2012). Acessibilidade a hospitais (Dissertação de mestrado). Programa de Pós-graduação em Engenharia Urbana, Universidade Federal de São Carlos, São Carlos.

Garcia, P. B. M., \& Raia, A. A., Jr. (2011). Acessibilidade a hospitais. In: Anais do XXV Congresso de Pesquisa e Ensino em Transportes (p. 692-695). Belo Horizonte.

Gotz, C., Frates, J., \& Weschler, S. (2009). Geographic Information Systems (GIS) in health organizations: emerging trends for professional education. The California Geographer, 49, 87-106.

Grava, S. (2004). Urban transportation system: choices for communities (805 p.). New York: McGraw-Hill.

Instituto Brasileiro de Geografia e Estatística - IBGE (2012). Características da população e dos domicílios: resultados do universo. Rio de Janeiro: IBGE. Recuperado em 10 de fevereiro de 2012, de http://www.ibge.gov.br/ home/estatistica/populacao/censo2010/caracteristicas_ da_populacao/default_caracteristicas_da_populacao.shtm.

Johnson, C. P., \& Johnson, J. (2001). GIS: a tool for monitoring and management of epidemics. In Map India 2001 Conference. New Delhi.

Mowforth, M. R. N. (1989). Trends in accessibility to employment in Greater London, 1971-1981. Transportation Planning and Technology, 13(2), 85-110. http://dx.doi. org/10.1080/03081068908717391.

Oliveira, I. C. E. (2001). Estatuto da cidade: para compreender... (64 p.). Rio de Janeiro: IBAM/DUMA.

Portugal, L. S. (Org.). (2012). Polos geradores de viagens orientados à qualidade de vida e ambiental: modelos e taxas de geração de viagens. (708p.). Rio de Janeiro: Interciência.

Rabelo, D. R., Leite, A. C. S., \& Morais, J. S. D. (2013). Análise geoespacial do atendimento à pacientes com dor torácica aguda em Fortaleza-CE. Revista Científica "Anap Brasil", 6(8), 1-11.

Raia, A. A., Jr., Galarraga, J., Albrieu, L., Sanánez, J. C., Gontijo, G. A. S., \& Meza, A. (2012). Hospitais e Estabelecimentos de Saúde. In L. S. Portugal. (Org.), Polos geradores de viagens orientados à qualidade de vida e ambiental (p. 120-140). Rio de Janeiro: Interciência.

Raia, A. A., Jr., Lopes, S. C., Dal Bó, M. L., \& Robles, D. G. (2008). Impactos da implantação de um Polo Gerador de Viagens: o caso do Hospital-Escola de São Carlos. In: Anais do V Congresso Luso-Moçambicano de Engenharia (p. 1-14). Maputo, Moçambique. Porto, Portugal: Edições INEGI.

Toledo, A. F., \& Demajorovic, J. (2006). Atividade hospitalar: impactos ambientais e estratégias de ecoeficiência. InterfacEHS, 1(2). Recuperado em 16 de junho de 2010, de http://www.interfacehs.sp.senac.br/br/artigos. asp?ed=2\&cod_artigo=29

URBE Planejamento (2013). Estudo de acessibilidade urbana para o Hospital do Subúrbio de Salvador. Recuperado em 15 de maio de 2013, de http://www.urbeplanejamento. com.br/urbe/?portfolio=estudo-de-acessibilidade

Vasconcellos, E. A. (1995). A crise do planejamento de transportes nos países em desenvolvimento: reavaliando pressupostos e alternativas. Transportes, 3(2),7-26.

Worcestershire County Council (2010). Worcestershire acute hospitals accessibility study. Worcestershire, UK: Worcestershire County Council. 
Worcestershire County Council (2011). Transport accessibility policy - worcestershire local transport plan 3. Worcestershire, UK: Worcestershire County Council.

Zhen, S. Q., \& Zhang, H. M. (2012). On centroid connectors in static traffic assignment: their effects on flow patterns and how to optimize their selections. Transportation Research Part B: Methodological, 46(10), 1489-1503. http://dx.doi. org/10.1016/j.trb.2012.07.006.

Recebido: Abr. 23, 2014

Aprovado: Jul. 31, 2014 